OPEN ACCESS

Edited by:

Richa Priyadarshini,

Shiv Nadar University, India

Reviewed by:

Rashmi Chandra,

University of Waterloo, Canada

Rajasri Yadavalli,

Chaitanya Bharathi Institute of

Technology, India

*Correspondence:

Kiran Bala

kiranb@iiti.ac.in

Specialty section:

This article was submitted to

Microbiotechnology,

a section of the journal

Frontiers in Microbiology

Received: 02 March 2021 Accepted: 11 November 2021

Published: 04 January 2022

Citation:

Samadhiya K, Sangtani $R$,

Nogueira $R$ and Bala K (2022)

Insightful Advancement and

Opportunities for Microbial Bioplastic

Production.

Front. Microbiol. 12:674864.

doi: 10.3389/fmicb.2021.674864

\section{Insightful Advancement and Opportunities for Microbial Bioplastic Production}

\author{
Kanchan Samadhiya ${ }^{1}$, Rimjhim Sangtani', Regina Nogueira ${ }^{2}$ and Kiran Bala ${ }^{1 *}$ \\ ${ }^{1}$ Department of Biosciences and Biomedical Engineering, Indian Institute of Technology, Indore, India, ${ }^{2}$ Institute for Sanitary \\ Engineering and Waste Management, Leibniz Universitaet Hannover, Hanover, Germany
}

Impetuous urbanization and population growth are driving increased demand for plastics to formulate impeccable industrial and biomedical commodities. The everlasting nature and excruciating waste management of petroleum-based plastics have catered to numerous challenges for the environment. However, just implementing various end-of-life management techniques for assimilation and recycling plastics is not a comprehensive remedy; instead, the extensive reliance on finite resources needs to be reduced for sustainable production and plastic product utilization. Microorganisms, such as bacteria and algae, are explored substantially for their bioplastic production repertoire, thus replacing fossil-based plastics sooner or later. Nevertheless, the utilization of pure microbial cultures has led to various operational and economical complications, opening the ventures for the usage of mixed microbial cultures (MMCs) consisting of bacteria and algae for sustainable production of bioplastic. The current review is primarily focuses on elaborating the bioplastic production capabilities of different bacterial and algal strains, followed by discussing the quintessence of MMCs. The present state-of-the-art of bioplastic, different types of bacterial bioplastic, microalgal biocomposites, operational factors influencing the quality and quantity of bioplastic precursors, embracing the potential of bacteria-algae consortia, and the current global status quo of bioplastic production has been summarized extensively.

Keywords: microbial bioplastic, polyhydroxyalkanoates production, mixed microbial cultures, algae-bacteria consortia, algae

\section{BIOPLASTICS “STATE-OF-THE-ART”}

The cataclysmic repercussions of disposable plastics on the environment have been a great deal of concern in today's scenario. The perennial nature of petroleum-based plastics instigates a conspicuous challenge for the ecological community in terms of their eradication and recovery. The recovery and recycling of plastic waste immensely depend on the method of disposal of plastic waste. The mixed disposal of plastic waste makes its recovery difficult and less energy efficient (Devasahayam et al., 2019). Several environmental and health-related issues are culminating every day due to extensive plastic production and usage, followed by infelicitous end-of-life management (Adane and Muleta, 2011). Apart from the convenient and cheap plastic products, single-use plastics (SUPs) have been rapidly making a mark within our busy 
and evolving society. Not only plastics are polluting our environment but also when exposed to various environmental factors like ultraviolet rays, temperature, etc., they break down into microplastic (MP), and this phenomenon can occur not only to disposed plastic but also the ones still in use. The chemicals that are used in manufacturing of SUPs (Phthalic acid esters) can transfer to the material contained within and travel to our food chain (Giacovelli et al., 2018; Chen et al., 2020).

The hike in plastic production has considerably surpassed any other human-made objects in the past 65 years. The complex nature of petroleum-based plastic leads to the deterioration of the environment at the expense of economic benefits. A seismic shift in the environmental policies effectuated by the overwhelming and escalating plastic pollution has redirected the prevailing maneuvers toward the advancement of native low-carbon, circular economies, with strict landfill waste regulation, systematic recycling and recovery methodologies, and compulsory usage of bioplastics for the production of innumerable commodities (Kaeb et al., 2016; Elmarasi, 2017; Godfrey, 2019). In order to reduce energy requirements and carbon footprint, researchers all over the world envision the replacement of fossil-based plastic with carbonneutral bio-based plastic for the betterment of the environment.

\section{Know-How of Microbial Bioplastics}

Bioplastics are biodegradable polymeric compounds composed of covalently bonded monomeric units. They are primarily derived from different biological sources, such as plants, bacteria, microalgae, and photosynthetic bacteria (Xia et al., 2021). Major components of the cells which include protein, polysaccharides, lipids, amino acids (Gonzalez-Gutierrez et al., 2010), and polyhydroxyalkanoates have been discovered as the key constituents of bio-based biodegradable plastics. Their accumulation is triggered in the microbial cell when subjected to varying physico-chemical perturbations (Samantaray and Mallick, 2015). Aliphatic polyesters, such as thermoplastic starch, polyhydroxyalkanoates, polybutylene succinate, and polylactic acid, have been acknowledged as the building block of the bioplastic products currently present in the market (Debuissy et al., 2018). Various bacterial strains including Bacillus sp., Azotobacter sp., Alcaligenes sp., Pseudomonas sp., methylotrophs, and Cupriavidus nectar as well as algal strains Spirulina platensis, Nostoc muscorum, Synechococcus sp., etc., have been explored extensively for the production of biopolymers (Lee, 1996; Steinbüchel and Füchtenbusch, 1998; Nishioka et al., 2001; Salehizadeh and Van Loosdrecht, 2004; Mallick et al., 2007; Toh et al., 2008; Babu et al., 2013; Hoarau et al., 2018).

Taking into consideration the prevailing plastic pollution and augmenting demand for plastic products, emphasizes on

\footnotetext{
Abbreviations: $\mathrm{CO}_{2}$, Carbon dioxide; COD, Chemical oxygen demand; HRAP, High-rate algal ponds; Lcl-pha, Long-chain length polyhydroxyalkanoate; Mcl-pha, Medium-chain length polyhydroxyalkanoate; MMC, Mixed microbial culture; $M_{w}$ Molecular weight; NADP, Nicotinamide adenine dinucleotide hydride; NADPH, Nicotinamide adenine dinucleotide phosphate hydride; PHA, Polyhydroxyalkanoate; PHB, Polyhydroxybutyrate; PHBH, Poly-(3-hydroxybutyrate-co-3-hydroxyhexanoate); PHBV, Polyhydroxybutyrate-co-valerate; PMC, photosynthetic microbial culture; PNSB, Purple non sulfur bacteria; PSB, Purple sulfur bacteria; Scl-PHA, shortchain-length Polyhydroxyalkanoate; SUP, Single-use plastics; VFA, Volatile fatty acid; VSS, Volatile suspended solid.
}

employing the biorefinery framework for cultivation of microalgae. Furthermore, while focusing on the biorefinery approach, it encompasses maneuvering the sustainable conversion of cell biomass into a spectrum of bio-based marketable products (bioplastics, biogas, bioethanol, pigments, protein, carbohydrates, and biofuels) to make microalgal biomass an economic-friendly and feasible feedstock for replacing the conventional plastic (Trivedi et al., 2015; Das et al., 2018; Chandra et al., 2019). Life cycle assessment (LCA) of various fossil-based and bio-based plastics has postulated that the usage and production of the later are advantageous over the former, primarily in terms of redemption of fossil reservoirs and attenuation of carbon emissions (Harding et al., 2007; Broeren et al., 2017). The bioplastics extracted from biomass feedstock and agricultural raw material tend to mimic various physical and mechanical properties of traditional plastics, and its substantial degradability by microbes has also been inferred by the researchers ( $\mathrm{Wu}$, 2012; Kim et al., 2020; Rocha et al., 2020). In the current view, agricultural feedstocks, such as wheat, sugar, potatoes, corn, rice, and soya, are subjected to fermentation to produce different types of bioplastics (Kadouri et al., 2005). However, continuing this practice might adversely influence the provision of food all over the world. Thus, the need for cost-effective bioplastic raw material, including microbial biomass, emerges out to be an effective solution for sustainable and feasible production of biodegradable or non-biodegradable bioplastic (Solaiman et al., 2006; Pakalapati et al., 2018).

However, the concurrent and critical scrutinization of bioplastic had suggested significant obligations in its development and commercialization, including the higher cost of bio-based substrates, microbe cultivation methodologies, and downstream processing. Perhaps, rethinking and considering the synergized cost of bioplastic production and waste management, while focusing mainly on various inexpensive biological substrates required for improved microbial growth, such as various effluents from industries, byproducts of industries like whey or crude glycerol or simply municipal waste (Amaro et al., 2019; Tamang et al., 2019; Wen et al., 2020) might give us a new perspective for economic and environmental evaluation of bioplastic regulatory framework comprising of its production, usage, and natural degradation. Carbon dioxide $\left(\mathrm{CO}_{2}\right)$, methane $\left(\mathrm{CH}_{4}\right)$, and syngas can also be used as an efficient substrate for the production of bio-based products, which further aids in the sequestration of greenhouse gases as well as in wastewater treatment (Sciarria et al., 2018; Pérez et al., 2020; Battashi et al., 2021). Additionally, for the cost-effective production of bioplastic, utilization of MMCs (photosynthetic or non-photosynthetic) has been proved to contribute efficiently, owing to the reduced cost of the mixed substrates involved. The usage of MMCs has been reported to facilitate the procurement of continuous culture without any contaminationrelated peril (Colombo et al., 2017; Figols et al., 2017; de Oliviera et al., 2019).

To accomplish the future agenda of worldwide usage of $100 \%$ bioplastic commodities, scientists are targeting the bioplastic production from various microorganisms. MMCs have been widely explored for optimizing their culture 
conditions, growth, bioplastic accumulation potential, and downstream processing techniques. Despite of great potential of MMCs for bioplastic accumulation, its commercialization is economically not feasible. Thus, it is crucial to thoroughly explore the MMCs for their full potential in terms of PHA production as well as other applications to reduce the cost of scale-up and downstream processing. Tailor-made consortia of microbes can be one such approach in this direction. Therefore, more basic information of the mechanism involved behind the synthesis of precursors of bioplastic in microbes, different critical factors, and unique characteristic of individual microbes in PHA synthesis is required. The present status of bio-based plastic in the market needs to be contemplated to unfold the efficiency of microbes yet not explored for bioplastic production. Hence, this review sheds light on the much-needed route exploration for utilization of microbes, specifically bacteria, algae, and MMCs, in the form of productive cell factories for sustainable bioplastic production on a commercial scale along with the development of retail markets of the same. It gives an insight into the status quo methodologies involved in the processing and production of bio-based building blocks constituting bioplastic. It also focuses on the usage of industrial waste effluents and byproducts as the substrate for the growth of pure (bacteria/algae) or mixed microbial cultures (MMCs) to make the process cost-effective and strengthen the phenomenon of circular bioeconomy.

\section{INSIGHT INTO THE DYNAMICS OF BIOPLASTIC PRODUCTION}

\section{PHA Biosynthesis Pathway}

Polyhydroxyalkanoate is a metabolite produced by some microorganisms as a storage product, which also acts as a shield against adverse environmental stress. Enhanced metabolic engineering methodologies have paved the way for exploring and exploiting various PHA biosynthesis pathways, which leads to the formation of different modified PHAs or bioplastics with specific material properties, beneficial for biomedical and industrial applications, such as high-value medical equipment (including sutures and drug delivery), or low-value materialistic bioplastic (cosmetics, coatings, food packaging, etc.; Keskin et al., 2017; Zhang et al., 2018).

Polyhydroxyalkanoates are quite essential building blocks for biodegradable plastic production. PHAs are classified into three categories based on their chain length, including shortchain-length PHAs (C3-C5), medium-chain-length PHAs (C6-C14), and long-chain-length PHAs (C14 and above; Brandl et al., 1988; Steinbüchel and Wiese, 1992; Witholt and Kessler, 1999; McChalicher and Srienc, 2007).

However, out of different types of PHAs produced, PHB (poly-3-hydroxybutyrate), a short-chain-length PHA, has been the most widely characterized and explored bioplastic due to its early discovery in the year 1926 (Lemoigne, 1926). PHB copolymers are synthesized by bacteria when various substrates are introduced interactively and are anticipated to result in the formation of bioplastic composed of either of two types of monomers, i.e., 4-hydroxybutyrate (4HB) and 3-hydroxy valerate (Anderson and Dawes, 1990; Byrom, 1992).

A brief illustration of the mechanism justifying the significance of nutrient-depleted/limited conditions is presented in Figure 1. Presence of ample amount of nutrients to the microbes, the Krebs cycle leads to the production of a high quantity of CoA, which in turn obliterates enzyme PhaA, 3-ketothiolase to block the accumulation of PHA. This redirects the flux of acetyl-CoA toward the Krebs cycle to accomplish cell growth and energy production. Conversely, when nutrients including phosphorus and nitrogen are not sufficient and an excess of carbon is added in the microbes' growth environment, a low amount of CoA is produced, which cannot obliterate the PHA biosynthesis enzyme. Consequently, channelizing the acetyl-CoA toward the PHA biosynthesis pathway stimulates PHA aggregation (Jung and Lee, 2000).

Furthermore, a comprehensive PHA biosynthesis pathway, as shown in Figure 1, comprehends the successive action of three prime enzymes (PhaA, PhaB, and $P h a C)$ responsible for culminating three essential reactions. At first, enzyme PhaA, i.e., $\beta$-ketoacyl-CoA thiolase, eventuates the reaction between two acetyl-CoA molecules for acetoacetyl-CoA formation. Subsequently, an enzyme PhaB, which is NADPH-dependent acetoacetyl-CoA dehydrogenase, catalyzes the reduction of acetoacetyl-CoA into (R)-3-hydroxybutyryl-CoA monomer. Eventually, enzyme poly-3-hydroxybutyrate polymerase, encoded as PhaC, instigates the polymerization of (R)-3hydroxybutyryl-CoA monomer into poly-3-hydroxyalkanoate (PHA; Madison and Huisman, 1999).

PHA synthesis is also reported to occur when fatty acids and sugar compounds are subjected to $\beta$-oxidation or de novo fatty acid biosynthesis pathways (Figure 1; Aldor and Keasling, 2003). The oxidation of carbon sources while neglecting the fatty acid $\beta$-oxidation pathway leads to the production of acetyl-CoA and transacylase enzyme $(P h a G)$, which further catalyzes the biosynthesis of PHA via the fatty acid de novo biosynthesis pathway. Whereas, when oxidation of carbon sources via the fatty acid $\beta$-oxidation pathway takes place then enzyme (R)-specific enoyl-CoA hydratase, PhaJ catalyzes the oxidization of enoyl-CoA to (R)-3-hydroxy acyl-CoA, which eventually acts as a target precursor for enzyme PhaC, PHA synthase, for PHA biosynthesis (Hoffmann et al., 2002; Muhammadi et al., 2015).

There are several other intertwined pathways aside from the three major pathways discussed above. Various anabolic and catabolic reactions take place inside the cells, which contributes in the production of PHA using different precursors. PHB being the most studied scl PHA does not limit the probability of production of numerous other PHAs. Raw material for conventional plastic is cheap to match the cost. Putative pathways have been a foundation of PHA synthesis strategies but to succeed in the battle between conventional plastic and biodegradable plastic, there is need to look at some non-intuitive pathways and focus on those non-competitive substrates. Precursors like amino acids, VFAs, and even greenhouse gases can contribute to PHA production. Bacteria can accumulate up to $80 \%$ of their dry cell weight when fed with carbon 


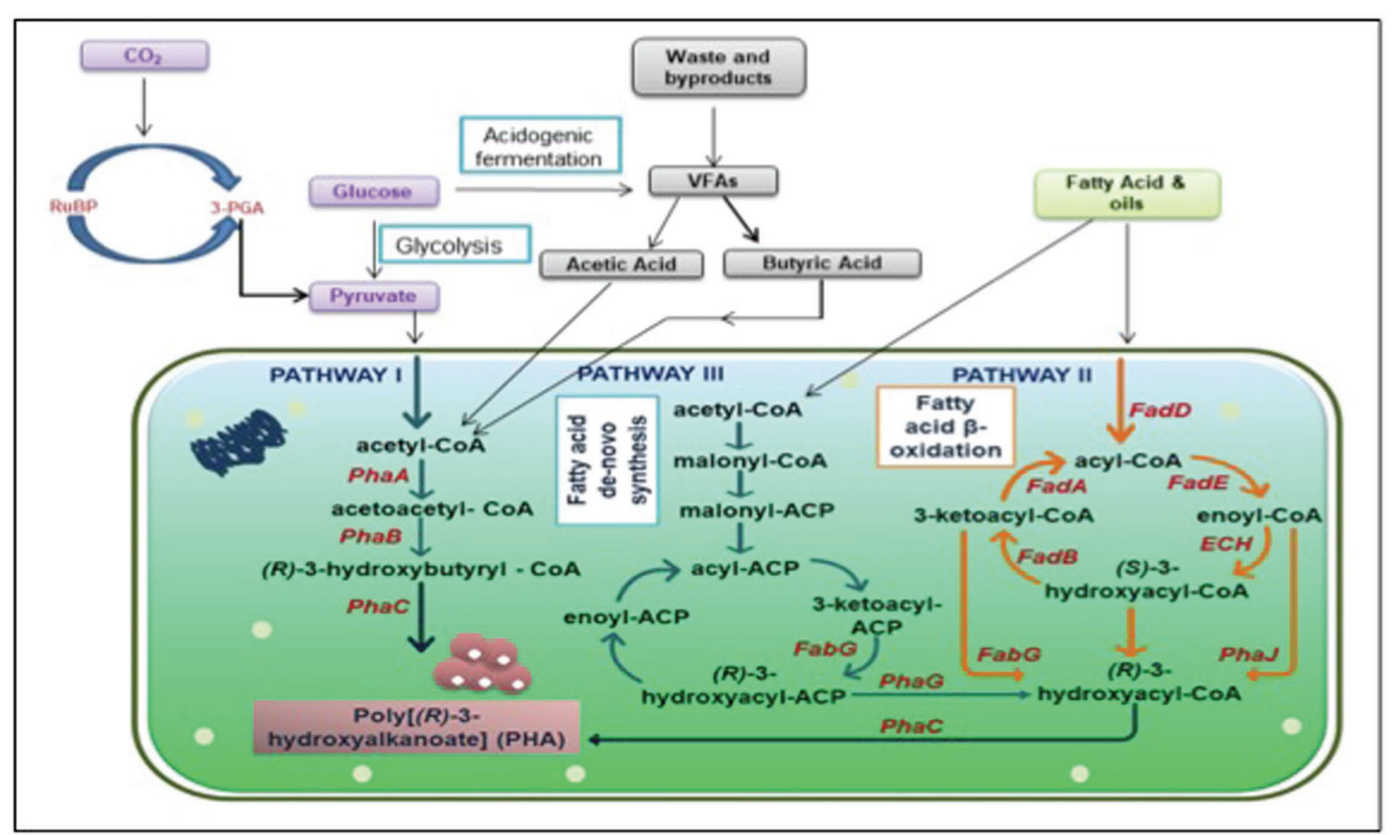

FIGURE 1 | Graphical illustration of interactive PHA biosynthesis pathway from different metabolites. PhaA: $\beta$-ketothiolase; PhaB: acetoacetyl-coenzyme A reductase; PhaC: PHA synthase; FabG: 3-ketoacyl acyl carrier protein (ACP) reductase; FadD: fatty acyl-CoA synthetase; FadA: 3-ketoacyl-CoA thiolase; FadE: acyl-CoA dehydrogenase; ECH: enoyl-CoA hydratase; FadB: 3-hydroxyacyl-coa dehydrogenase PhaJ: enoyl-coenzyme A hydratase; PhaG: (R)-3-hydroxydecanoylACP: CoA transacylase; RuBP: Ribulose 1,5-bisphosphate; 3PGA: 3 phosphoglyceric acid; $\mathrm{CO}_{2}$ : Carbon dioxide; and VFAs: Volatile fatty acids.

TABLE 1 | Different types of PHA accumulated by bacteria under varying substrate supplementation.

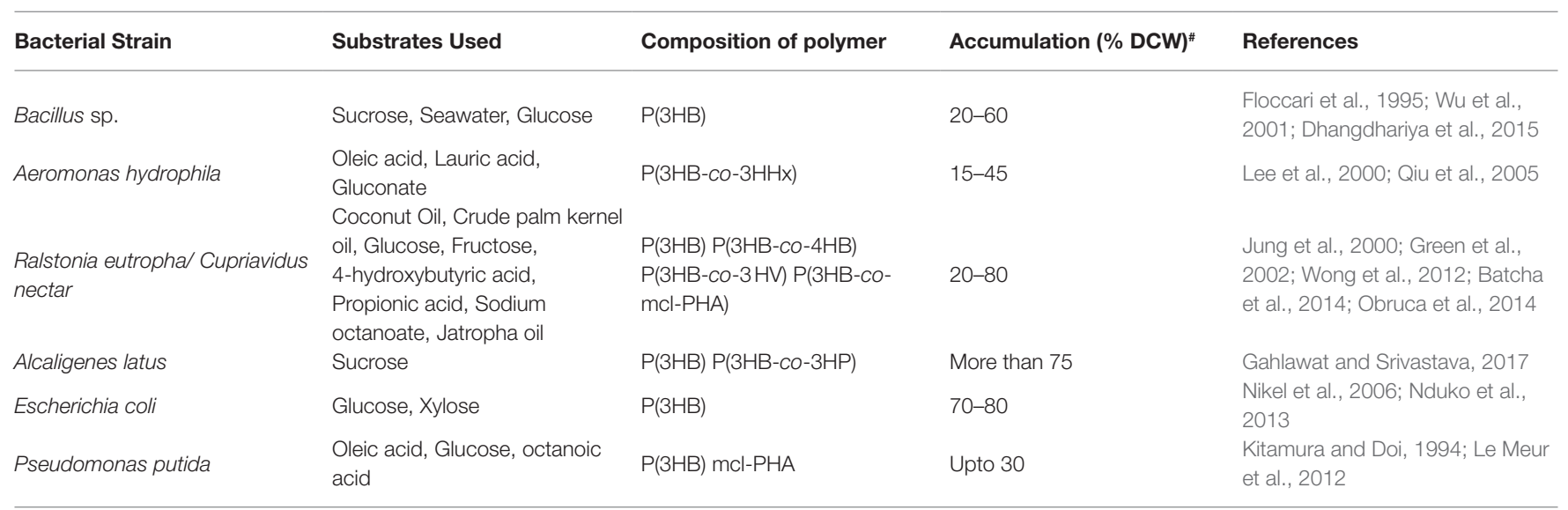

\#DCW, \% Dry Cell Weight.

PHA, Polyhydroxyalkanoate; $P(3 H B)$, poly(3-hydroxybutyrate); $P(3 H B-c o-3 H H x)$, poly(3-hydroxybutyrate-co-3-hydroxyhexanoate); $P(3 H B-c o-4 H B)$, poly (3-hydroxybutyric acid-co-4hydroxybutyric acid); $P(3 H B-c o-3 H V)$, poly(3-hydroxybutyrate-co-3-hydroxy valerate); $P(3 H B-c o-3 H P)$, poly(3-hydroxybytyrate-co-3-hydroxypropionate); mcl-PHA, medium-chainlength polydroxyalkanoate.

sources (Budde et al., 2011). Several other bacteria mentioned in Table 1 and section 3 can utilize different carbon sources and accumulate PHA but valorization of these carbon sources are species-specific (García et al., 1999). Few other precursors could be volatile fatty acids, such as acetate, butyrate or propionate, amino acids, and gases like carbon di oxide or methane (Figure 1).

Significance of metabolic pathways in the production of any biotechnologically important metabolites is known worldwide; however, detailed know-how of every reaction, its reactants, and products along with the knowledge of enzymes involved needs to be gathered primarily before targeting the production of the metabolite of interest. PHA being a type of bioplastic precursor, the understanding of its biosynthesis pathway gives an insight into the nature of catalyst involved, role of varying physico-chemical factors, and even about the type of nutrient media required for diverting the carbon flux toward increased production of PHAs. Another scientific boom in the last decade 
has been machine-learning approach. With the help of already present database and pathways, various algorithms can be used and analyze the optimum culture conditions related to the selected host (Li et al., 2020). Genome-scale study can also help selecting the organism suitable for specific application (Nobu et al., 2014; Nazem-Bokaee and Senger, 2015).

The diversion of carbon flux in response to diverse environmental stress conditions can be determined by studying the PHA production pathway and its understanding will further aid in optimizing the growth conditions of the microbe or will help in carrying out the genetic manipulation, while targeting upregulation or downregulation of genes involved in the formation of reactants, products, or an enzyme. A deep comprehension of intuitive and non-intuitive metabolic pathway will aid in targeting the raw material in conjucture with the organism and also scrutinizing organisms for a tailor-made consortium for soaring PHA production.

\section{Factors Influencing Bioplastic Precursor Accumulation}

Establishing a sustainable and commercial process for bioplastic production has two main components: quantity and quality of accumulated precursor. High quantity will ensure sustainability of the process but on the other hand, if the properties, which determine equivalence of bioplastic with conventional plastic, will be surpassed, it will fail to make its place in the market.

Properties like crystallinity, glass transition temperature, thermal stability, and melting temperature determine the quality of the polymer (Ten et al., 2015). Homopolymers often suffer from the disadvantage of being brittle; hence, production of copolymers is sought to overcome the hurdle (Bhati and Mallick, 2015). In this section, factors that affect the accumulation of bioplastic precursors are discussed.

Primarily, strain selection plays a very important role in determining the percentage and type of bioplastic precursor being produced. The chemical and physical properties of the bioplastic have been analyzed to be highly dependent on the type of PHA accumulated by different strains. Alcaligenes latus has been reported to produce scl PHA, whereas mcl-PHA is commonly produced by Pseudomonas putida (Wang and Lee, 1997; Sun et al., 2007).

Another important factor that affects the PHA accumulation potential of microorganism is the composition of nutrient media. The deficiency of essential nutrients or supplementation with waste (rich in carbon sources, amino acids, or fatty acids) has been delineated to influence PHA production. Even the mechanical properties of PHA material get modified based on the nutrients present in the media and it eventually characterizes the use of bio-based material in different fields of biotechnology. PHB yield of Bacillus megaterium subjected to various physicochemical parameters was investigated by Mohanrasu et al. (2020) and concluded that optimization of parameters, such as $\mathrm{pH}$, nitrogen, and carbon sources, needs to be optimized for each bacterial species for the productive accumulation of good quality PHA.
Various nutrients and physico-chemical factors play a role in the biosynthesis pathway of PHA accumulation (Figure 1). Three key enzymes of PHA accumulation are phaA (ketothiolase), phaB (Acetoacetyl reductase), and phaC (PHA synthase). Several copies of PHA synthase gene have been reported over 30 genera of bacteria. All of these genes produce different types of PHA synthase, which determines the conversion of substrate into PHA. It also determines the molecular weight of PHA being produced (Rehm and Steinbüchel, 1999). Molecular weight of PHA determines the crystallinity and thermal stability of bioplastic (Laycock et al., 2014). PHA synthase has three classes that produce PHA with different molecular weight. Class I of PHA synthase produces high molecular weight PHA ranging from $500 \mathrm{kDa}$ to a few millions, class II produces $50 \mathrm{kDa}$ to $500 \mathrm{kDa}$, whereas class III PHA synthase product's molecular weight ranges in between (Rehm and Steinbüchel, 1999). High molecular weight also increases young's modulus which determines the elasticity of the bioplastic (Domínguez-Díaz et al., 2015). Few studies have reported influence of different carbon sources on molecular weight. Paraburkholderia xenovorans LB400 was grown in three different carbon sources namely, glucose, xylose, and mannitol. The study concluded that PHB produced with glucose and xylose had similar molecular weight, which is near to commercially available PHB, whereas PHB produced in mannitol supplementation had double $M_{w}$ as compared to control and other carbon sources. The study also concluded that carbon sources not only affect the quantity of PHA production but also the molecular weight of bioplastic (Sanhueza et al., 2020).

Furthermore, the PHB accumulation capacity of carbonsequestering microalgae, Botryococcus braunii, has been evaluated and validated statistically by optimizing different parameters, including temperature, $\mathrm{pH}$, and substrate concentration of sewage wastewater. To some extent, these process parameters were found responsible for diverting the carbon flux toward the enhanced production of PHB. Usage of sewage wastewater as an inexpensive nutrient substrate for algae-based bioplastic production indicated that this strategy could be adopted at an industrial scale for economically feasible and beneficial large-scale PHB production. Microalgae, B. braunii was claimed and recommended as a potential candidate for PHB production (around 20\% of dry algal weight), which can be used in the pharmaceutical industry. NADH plays a major role in the assimilation of pentose and hexose sugars. Activation of glucose transporters releases $\mathrm{NADH}$, which in turn activates the accumulation of PHA via inducing conversion of acetyl coA (Kavitha et al., 2016a,b).

Likewise, Chlorella fusca LEB 111 microalgae have also been examined experimentally for improved PHB production by optimizing the requirement of pentose sugar substrate, photoperiod, and light intensity factors, which contribute significantly to the accumulation of PHB. It was demonstrated that $28 \mu \mathrm{mol}$ photons $\mathrm{m}^{-2} \mathrm{~s}^{-1}$ of light intensity, $6 \mathrm{~h}$ exposure to light, and xylose supplementation induced the microalgae to synthesize $17.4 \%(\mathrm{w} / \mathrm{w})$ PHB. Therefore, deviation in the light periodicity integrated with varying luminous intensities and involvement of pentoses in the metabolic pathway has 
proven to stimulate and boost the PHB accumulation capacity of Chlorella. The uptake of organic carbon is highly dependent on photoperiod and light intensity. Light phase triggers the enzymes responsible for autotrophic growth hence blocking the utilization of carbon sources but during the dark cycle of mixotrophy, it starts assimilating organic carbon hence converting the flux toward PHA synthesis (Cassuriaga et al., 2018).

Irrespective of the significance of either of the microbes, i.e., bacteria or algae in the production of bioplastic, the accumulation of metabolite in the cell along with the growth of microorganism has been delineated to depend highly on various physico-chemical parameters and environmental conditions present at the time of cultivation of microbes. Physical and chemical parameters, such as type of fermentation, type of growth conditions, time of harvesting, aeration, presence or absence of oxygen, $\mathrm{pH}$, temperature, light intensity and the composition of nutrient media, have been studied immensely by researchers for optimizing maximum biomass growth and PHA accumulation of microbe of interest. However, the type of microbe and its strain influences the quality and quantity of the bioplastic produced. Individual microbial cultures will limit the quality and quantity of produced bioplastic; therefore, different algal and bacterial strains need to be studied and the influence of various influential parameters needs to be optimized.

\section{PROSPECTS OF BIOPLASTIC PRODUCTION IN PURE CULTURES}

\section{Bacterial Cell Factories}

Bacteria are the supreme cell assemblies producing high molecular weight biomolecules, assembled by the linkage of building blocks, such as hydroxy fatty acids, sugars, and amino acids via catalytic enzymes, to formulate a diverse range of bioplastic with varying mechanical and chemical attributes. Biomolecules, such as polysaccharides (consist of sugar moieties intertwined by glycosidic bonds), polyamides (comprise of amino acids intertwined by peptide linkages), polyesters (consist of esterbond linked hydroxy fatty acids), and polyphosphates (composed of inorganic phosphates connected by anhydride bonds), are produced by different bacterial species. These have been made and utilized substantially on a commercial scale while considering the recent advances in bioengineering methods and molecular techniques (Muhammadi et al., 2015; Schmid et al., 2015; Wang et al., 2016; Wendisch et al., 2018). French researcher Maurice Lemoigne discovered the first-ever known bioplastic - PHB in 1926 while prospecting the bacterium Bacillus megaterium (Lemoigne, 1926). PHAs are linear polyesters produced and deposited as water-insoluble, amorphous, and intracellular spherical inclusions or granules of $0.2-0.7 \mathrm{~mm}$ via PHA metabolism (Girotto et al., 2015). Wide range of bacteria (Gram-negative and Gram-positive) is reported to synthesize PHA, with varying composition, resulting in immensely diversified materialistic properties (Schubert et al., 1988; Steinbüchel et al., 1992; Rehm et al., 1998; Rehm and Steinbüchel, 1999; Rehm, 2003).
PHAs are highly popularized on a commercial scale because they resemble oil-based plastic properties, such as their thermoplasticity, depicted by 30 to $70 \%$ crystallinity and $50-180^{\circ} \mathrm{C}$ melting temperature, making them a perfect fit in the bioplastic industry as biodegradable and renewable bioplastic. A detailed description of several bacteria producing different types of PHAs under the supplementation of varying substrates has been listed in Table 1 (Jendrossek, 2009; Kai and Loh, 2014; Favaro et al., 2019).

According to the previous research done on PHA, it is postulated that as compared to the PHA accumulation in plants, which is less than $10 \%$ dry cell weight, bacteria have the potential to accumulate the magnificent amount of PHA (90\% dry cell weight; Steinbüchel and Lütke-Eversloh, 2003; Verlinden et al., 2007). It has been elucidated that based on the requirement of varying constraint conditions, PHA-producing bacteria can be categorized into two groups: non-growth assisted and growth assisted. The bacterial strains, such as Protomonas extorquens, A. eutrophus, Cupriavidus necator, Protomonas oleovorans, Pseudomonas sp. 2F, and Methylmonas extorquens, are some of the microbes that aggregate enhanced PHA in nutrientdeprived/limited (including, nitrogen, phosphorus, magnesium, and sulfur) and excess carbon supplemented environment (Braunegg et al., 1998; Ciesielski et al., 2010), whereas another class of bacteria, such as Alcaligenes latus, Paracoccus denitrificans, Azohydromonas lata DSM 1122, and Pseudomonas putida GPol ATTC 29347, synthesizes PHA without the need of nutrientlimited conditions (Byrom, 1994; Hartmann et al., 2006; Koller et al., 2010; Anjum et al., 2016).

The pure culture of bacterial strains, such as Bacillus, Azotobacter, Nocardia, Alcaligenes, Pseudomonas, Ralstonia eutropha, and Rhizobium, is considered extensively for commercial production of PHB (Chaudhry et al., 2011; Jiang et al., 2011a; Chandani et al., 2014). Budde et al. have reported that bacterium Cupriavidus necator H16 (earlier known as Ralstonia eutropha), when supplemented with fructose as carbon supply, can potentially accumulate $79 \%$ of the dry cell mass of PHB under optimal conditions (Budde et al., 2011).

Concurrently, the commencement of genetic engineering approach for refining all the stages of the PHA production process, mostly related to the types of substrates up taken and utilized, has laid a cornerstone in the field of bioplastic production. For instance, intra-genus PHA genes cloned and expressed in E. coli from Azotobacter sp. have shown up to $72 \% \mathrm{PHB}$ accumulation with corn steep liquor as carbon and nitrogen source. There are different examples of genetic manipulation done to achieve an elevated amount of good quality PHA without compromising the cell growth (Povolo et al., 2010; Liu et al., 2011; Chen and Jiang, 2018; Ouyang et al., 2018).

In spite of extensive research and genetic manipulation from more than three decades, the cost of bioplastic has yet not been able to match that of conventional plastic, the key rationale being high cost of the substrate. For a cost-effective production of PHA, researchers have reckoned photosynthetic bacteria. Photosynthetic bacteria can be divided into cyanobacteria, purple bacteria, and green bacteria. Purple bacteria are anoxygenic bacteria, which means they do not produce oxygen during 
photosynthesis. They use sulfur (purple sulfur bacteria PSB) or hydrogen or ferrous ions (purple non-sulfur bacteria PNSB) as an electron acceptor during photosynthesis (Mothersole et al., 2018). They can be used for protein accumulation, heavy metal absorption as well as PHA production (Talaiekhozani and Rezania, 2017; Alloul et al., 2019; Foong et al., 2019).

Both PSB and PNSB can accumulate PHA under autotrophic and heterotrophic conditions. In a study, 12 strains containing nine PNSB and three PSB were exposed to organic and inorganic carbon as well as a mixture of both under nitrogen starvation and PHA accumulation was observed. Organic carbon yielded a higher accumulation of PHA as compared to inorganic carbon. Rhodovulum visakhapatnamense accumulated up to $30 \%$ accumulation and Rhodovulum sulfidopilum when exposed to only acetate in seawater accumulated 9\% PHA (Higuchi-Takeuchi et al., 2016). PNSB prefer VFAs as a precursor for the production of PHA (Higuchi-Takeuchi and Numata, 2019). Acetate is considered the best precursor for PHB synthesis, having least steps involved in the conversion. Other VFAs like propionate, butyrate, and valerate also have a high assimilation rate during the metabolism of PNSB. A proteomic study revealed that VFAs are responsible for rapid and high accumulation of PHA in PNSB; however, bicarbonate is also important in the assimilation of valerate and other volatile fatty acids except for acetate in Rhodospirillum rubrum (Bayon-Vicente et al., 2020).

As it has been established before that purple bacteria favor VFAs over other carbon sources, studies have been conducted to find cheaper alternatives of VFAs from waste. Palm olive mill waste has high VFA and chemical oxygen demand (COD) which was utilized by Rhodopseudomonas sp. S16-FVPT5 to accumulate $315 \mathrm{mg} / \mathrm{l} \mathrm{PHB}$ and 2,236 ml/l hydrogen (Carlozzi et al., 2019). They can also valorize high lignin-containing waste after thermal treatment and convert it into 21\% PHB of their dry cell weight (Allegue et al., 2021).

It is evident that the bioplastic precursors derived from bacteria prove to be an imperative constituent of bioplastic commodities. There are several plastic industries worldwide, manufacturing bioplastic products from the precursors derived from bacteria, and the products have the potential of replacing fossil-based plastic. However, large-scale production of bacterial bioplastic has started from past few years and to make the process feasible as that of conventional plastic production, more research needs to be performed in this domain. The factors affecting the accumulation of bioplastic precursors, their extraction and purification process, and at last their transformation into bioplastic commodities need to be investigated on a large scale. The evaluation needs to be done to explore the bioplastic production capability of pure strains as well as MMCs. The biorefinery approach for the production of bacterial bioplastic along with other essential bioproducts derived from bacteria needs to be scrutinized and exercised in order to make the process techno-economically feasible. Additionally, systems analysis incorporating LCA and techno-economic analysis must be investigated for determining the sustainability of bacterial bioplastic production.

\section{Algal Bioplastic}

For years, photosynthetic organisms, such as microalgae and cyanobacteria, have been highly explored for their involvement in trapping solar energy and balancing the atmospheric carbon (Ghosh and Kiran, 2017). The crucial life elements, including solar energy, $\mathrm{CO}_{2}$, and water, are processed through microalgae metabolism to form bioenergy products. Because of their high cell proliferation rate, microalgae's conversion efficiency is postulated to be 10 to 50 times higher than that of terrestrial plants. Thus, the microalgal land footprint required for bioenergy production is significantly less than plants. The most prevalent and topical agenda in the field of algal biotechnology is accomplishing the tremendous opportunities catered by algal biomass and their widespread biochemical portfolio. Due to their exceptional potential of assimilating photosynthetic carbon, microalgae are enunciated as a highly efficient form of cell biomass produced and has immense potential to engage in a clean energy future (Kiran et al., 2014). Economic constraints obviate many emerging commercial endeavors, and a lot of such barriers can be conquered by incorporating a diligent conceptual configuration for augmenting the algal biomass values (Laurens et al., 2017).

As a spin-off from algal biofuels, algae are recognized as proficient producers of various exclusive metabolites, such as polyunsaturated fatty acid, carotenoids, phycobilins, polyhydroxybutyrate, and so on, which are of commercial importance in pharmaceutical, nutritional, plastic, cosmetic, and other biotechnology-based industries (Laurens et al., 2017; Martosa et al., 2019; Arun et al., 2020). Additionally, microalgae being a phototroph, consumes inorganic nutrients, such as nitrogen, phosphorus, sulfur, and carbon dioxide along with solar energy for biomass proliferation and cell growth. The growth prerequisites for microalgae are expedient compared to that of heterotrophs, such as bacteria and yeast. Due to the requirement of organic nutrients by bacteria for accumulating imperative metabolites, makes the cultivation model of heterotrophs expensive. It is deduced that while taking into account the production cost of bacterial bioplastic, the largest contributing factor in the hiked production cost is the usage of tremendous amount of organic substrate for fermentation process, followed by the cost and energy-intensive PHA extraction procedures, eventually making the bacterial bioplastic production economically infeasible (PerezGarcia et al., 2011; Markou and Nerantzis, 2013; Karan et al., 2019). Comparatively, the commercialization of microalgal bioplastic is hindered by the high cost involved in the traditional phototrophic cultivation techniques. Hence, presently, microalgae-derived bioplastic appears to be infeasible compared to the conventional processes but synergized cultivation of microalgae together with the treatment of wastewater paves the way for the reduced commercialization cost. The production of microalgae-emanated bioplastics has been consummated through different research methodologies, including (1) amalgamation of microalgae biomass with bio-based or fossil-based plastics or their additives (2) complete usage of microalgae biomass in the form of bioplastic (3) improving the metabolite (of interest) accumulation capacity of specific microalgal species along with its cost-effective extraction (4) processing microalgae bioplastic while obeying the biorefinery 
model, and lastly (5) administrating genetic engineering methodologies for the creation of proficient microalgal strain to synthesize an ideal bio-based plastic (Jungmeier, 2014).

\section{Accumulation of Bioplastic Precursor in Algae}

Bioplastic production from microalgae is considered to be an efficacious strategy for direct carbon entrapment (by mitigating $\mathrm{CO}_{2}$ produced from flue gas), accompanied by the acquisition of imperative biochemical constituents, including lipids (Ho et al., 2014; Nakanishi et al., 2014; Anand et al., 2019), proteins (Schwenzfeier et al., 2011), carbohydrates (Ho et al., 2013; Cea-Barcia et al., 2014), and PHA (Roja et al., 2019) that can act as potential bioplastic feedstock. Ultimately, establishing the fact that $\mathrm{CO}_{2}$ sequestered by bioplastic-producing microalgae is directly getting entrapped in the form of polymer and not exiting into the environment (Abdul-Latif et al., 2020; Crocker et al., 2020).

In addition to that, supplementation of organic nutrients to activate the organism's heterotrophic metabolism, along with the addition of varying combinations of crucial nutrients, to accomplish the synthesis of aggravated PHA can effectuate a cost-effective cultivation model for microalgal bioplastic synthesis (Table 2; Dietrich et al., 2017; Silva et al., 2017; Di Caprio et al., 2019a,b; Karan et al., 2019; Abiusi et al., 2020). Conclusively, varying physical and chemical nutrient conditions of microalgae have been recognized to influence the quality and quantity of metabolites being produced stupendously; thus, perturbing conditions can be exploited and scrutinized further for boosting the production of a metabolite of our interest, such as polyhydroxyalkanoate (PHA; Gualtieri, 2001; De Morais and Costa, 2007; Hossain et al., 2008; Noreen et al., 2016). A perspective that starch-based bioplastics could be made from the starch-rich $(49 \% \mathrm{w} / \mathrm{w})$ biomass of microalgae, such as

TABLE 2 | Algal species accumulating different forms of bioplastic.

\begin{tabular}{|c|c|c|c|}
\hline Algal Strain & Type of Polymer & $\begin{array}{c}\text { Accumulation } \\
(\% \mathrm{DCW})^{\#}\end{array}$ & References \\
\hline Nostoc muscorum & $\mathrm{PHB}$ & $31-69$ & $\begin{array}{l}\text { Sharma and } \\
\text { Mallick, 2005; } \\
\text { Samantaray and } \\
\text { Mallick, } 2014\end{array}$ \\
\hline $\begin{array}{l}\text { Phaeodactylum } \\
\text { tricornutum }\end{array}$ & $\mathrm{PHB}$ & 10.6 & $\begin{array}{l}\text { Hempel et al., } \\
2011 \\
\text { Maheswari and }\end{array}$ \\
\hline Spirulina platensis & $\mathrm{PHB}$ & 6.20 & $\begin{array}{l}\text { Ahilandeswari, } \\
2011\end{array}$ \\
\hline $\begin{array}{l}\text { Botryococcus } \\
\text { braunii }\end{array}$ & $\mathrm{PHB}$ & $20-60$ & $\begin{array}{l}\text { Kavitha et al., } \\
\text { 2016a, 2016b }\end{array}$ \\
\hline $\begin{array}{l}\text { Synechocystis sp. } \\
\text { PCC } 6714\end{array}$ & $\mathrm{PHB}$ & 37 & $\begin{array}{l}\text { Kamravamanesh } \\
\text { et al., 2017, } 2018\end{array}$ \\
\hline $\begin{array}{l}\text { Chlorella fusca } \\
\text { LEB11 }\end{array}$ & $\mathrm{PHB}$ & 17.4 & $\begin{array}{l}\text { Cassuriaga et al., } \\
2018\end{array}$ \\
\hline $\begin{array}{l}\text { Microcystis } \\
\text { aeruginosa }\end{array}$ & PHB & 4.38 & Abdo and Ali, 2019 \\
\hline Scenedesmus sp. & $\mathrm{PHB}$ & $1-30$ & García et al., 2021 \\
\hline
\end{tabular}

\#\%CW\% Dry Cell Weight.

$P H B=$ Polyhydroxybutyrate.
Chlamydomonas reinhardtii $11-32 \mathrm{~A}$ by exercising efficient plasticization through the twin-screw extrusion process was established (Mathiot et al., 2019).

Kato (2019) also reported that triacylglycerol-rich algal biomass of Chlamydomonas reinhardtii could be molded, in the crude form, directly into $7 \mathrm{~mm}$ bioplastic beads that can withstand compressive stress of up to 1.7 megapascals, thus excluding the cost of extraction and purification processes involved in the bioplastic production. Amidst all the metabolites produced, polyhydroxyalkanoate (PHA) is the highly explored and most expedient building block of microalgae bioplastic due to its easy biodegradation, catalyzed by enzymes (Shi et al., 2012; Noreen et al., 2016; Rahman and Miller, 2017; Karan et al., 2019; Beckstrom et al., 2020). The production of polyhydroxybutyrate from microalgae in high-rate algal pond (HRAP) was analyzed along with their plasticization capacity, and it was concluded that out of two microalgal strains, Microcystis aeruginosa, exhibited the highest $\mathrm{PHB}$ concentration. However, high-rate algal pond biomass dominated with $M$. aeruginosa showed the highest $\mathrm{PHB}$ concentration and was utilized for the production of bioplastic (Abdo and Ali, 2019).

Microalgae being oxygenic photoautotroph can also grow in other modes like heterotrophy or mixotrophy (Gong and Huang, 2020). Cyanobacteria can accumulate PHA in photoautotrophic modes as reported previously under controlled conditions $(4.5 \%)$ or under phosphate limitation (11\%; Panda and Mallick, 2007). Many other reports have also established a relationship with mixotrophic and heterotrophic production of bioplastic by several cyanobacteria like Nostoc muscorum, Synechocystis sp., and Microcystis sp. (Table 2; Bhati and Mallick, 2012; Gopi, 2014; Abdo and Ali, 2019).

Microalgae are now being approached by researchers very rapidly for PHA production as well (Roja et al., 2019; García et al., 2021). But using pure substrate and maintaining pure culture at a large scale for PHA production will still fall short at economic point of view. Hence, inducing non-intuitive pathways via physico-chemical stress or adapting different approaches and application of microalgae in PHA production is far-reaching (Chalima et al., 2017; Llamas et al., 2020).

\section{Algal Biocomposites}

Researchers also addressed the formation of an innovative algal composite comprising of Chlorella sp. (hydrophilic, granular, and biofix $\mathrm{CO}_{2}$ efficiently) and materials, such as polyvinyl chloride (hydrophobic), polyethylene, and polypropylene. The algal composite is characterized as a composite of high tensile strength and thermal stability due to the presence of Chlorella grains and their binding capability (Zhang et al., 1999, 2000a,b; Otsuki et al., 2004). Lee et al. used red algae, Gelidium elegance, to produce poly butylene succinate-based biocomposites by the compression molding process. The study suggests that bleached red algae fiber can be incorporated for manufacturing environmental-friendly biocomposites (Lee et al., 2008). Chiellini et al. produced eco-compatible hybrid biocomposites using green algae fibers and polyvinyl alcohol polymers (Chiellini et al., 2008). Intuitively, encapsulation of algal biomass of Nannochloropsis sp. and Spirulina sp. in thermoplastic polymers, 
such as polypropylene, polyurethane, and polyethylene, suggested that manufacturing plastic based on algae is a prudent and imperative mechanism to sequester and retain atmospheric $\mathrm{CO}_{2}$ fixed proficiently by algae (Shi et al., 2012). Moreover, while considering the biorefinery model of microalgal species, such as Botryococcus braunii and Nannochloropsis gaditana, integration of residual microalgal biomass left after the extraction of biodiesel with biodegradable polymers poly butylene succinate and poly butylene adipate-co-terephthalate, respectively, revealed that the residual biomass could be scrutinized further to fabricate biocomposites in a cost-effective manner (Toro et al., 2013; Torres et al., 2015).

Furthermore, in pursuance of microalgal bioplastic production, Zeller and colleagues in 2013 illustrated the significance of polymerization of protein-rich microalgae biomass thermomechanically to synthesize algae-based bioplastic as well as thermoplastic blends or biocomposites. The biomass of Chlorella sp. and Spirulina sp. consisting of a high amount of protein, i.e., 58 and 57\%, respectively, was integrated with varying glycerol concentrations and mechanical testing of bioplastic was performed through thermo-mechanical molding by preparing ASTM standard "dog bones." The bioplastic mix produced was further blended with polyethylene polymer and was observed that Spirulina was more compatible with polyethylene as compared to Chlorella, exhibiting significant mechanical properties, making the blend suitable for commercial usage. However, pure Chlorella-based bioplastic, without any blend, displayed better bioplastic properties, such as high tensile strength along with superior extension and loading properties, than pure Spirulina-based bioplastic (Zeller et al., 2013). Sabathini et al. (2018) also illustrated that the eco-sustainable plastic film made from pre-treated Chlorella and polyvinyl alcohol mixture could perform favorably for manufacturing packaging plastic material due to its increased bioplastic tensile strength as well as elongation percentage.

\section{Genetic Manipulation for Microalgal PHB Accumulation}

Microalgae Phaeodactylum tricornutum was investigated by Hempel et al. for its ability to act as a photosynthetically active bioreactor to synthesize bio-based plastic. For the first time, the solar-powered microalga was proclaimed to serve as an efficient biosynthetic expression factory when the $\mathrm{PHB}$ production pathway of bacterium Ralstonia eutropha H16 was incorporated into the biochemical pathways or metabolism of P. tricornutum to synthesize building blocks of bioplastics, such as PHB. The granular PHB accumulated after bacterial enzyme expression was determined to be $10.6 \%$ of the dry algal weight (Peplinski et al., 2010; Hempel et al., 2011).

PHB biosynthesis genes for enzymes PhbB and PhbC derived from bacterium $R$. eutropha were incorporated into microalga C. reinhardtii for $\mathrm{PHB}$ production. It already had the gene for the enzyme PhbA, essential for PHB biosynthesis. The research illustrated that the algae $C$. reinhardtii was able to accumulate $6 \mathrm{mg} / \mathrm{g}$ dry cell weight of PHB after the expression of bacterial genes (Chaogang et al., 2010). The studies mentioned earlier manifest likelihood of formation of a genetically modified microalgae for the production of PHA, but scaling up of a process with GMOs have their own drawbacks circling back to the cost-effectiveness of bioplastic production and commercialization (Beacham et al., 2017). Entailing another approach for uncovering the true potential of microbes for PHA synthesis is a must.

\section{Algal Bioplastics Predicaments and the Upcoming Resolutions}

The synthesis of algae-based bioplastic comes with many challenges, and unraveling the complications needs to be the prime target for designing the upcoming research initiatives. For instance, bioplastic materials comprising algae-derived lipids are proclaimed to emit displeasing odors, thus confining the range of products of such bioplastics. Similarly, the characteristic of sugars or carbohydrates to form an aggregate inside the algal biomass leads to prolonged production and extraction steps, making it time and money-consuming. However, regardless of these hindrances, mechanical characteristics exhibited by algae-derived bioplastics are much better than their fossil-based analogs. The superior quality is attributed to the process of microalgae protein getting stretched and intermingled into the polymer matrix, establishing the significance of protein-rich microalgal biomass to produce high-quality bioplastic. Therefore, the biorefinery model for microalgae cultivation can be incorporated proficiently to synthesize lipid or carbohydrate-based biofuels and simultaneously accumulate integral monomer units formulating into bioplastics, thus reducing the extraction and manufacturing cost involved during algae-based plastic production (Beckstrom et al., 2020).

In a nutshell, algal bioplastic production is still in its infancy as compared to bacterial bioplastic production. Besides, the waste to bioenergy conversion potential of algae has not been explored to the fullest for the treatment of waste (wastewater, food wastewater, and industrial waste) coupled with the production of bioplastic precursors. Even co-production and extraction of different bioproducts in an algal biorefinery have been researched evidently, but the accumulation of bioplastic in a biorefinery setup has not yet been reviewed. The potential of different algal strains, their growth, utilization of waste (exhaust $\mathrm{CO}_{2}$ as well wastewater), and co-production of bioplastic along with other valuable products in a biorefinery setup needs to be envisioned to accomplish the objective of $100 \%$ bio-based plastic.

Consequently, the entrapment and storage of carbon dioxide permanently in algal biomass have also been achieved by encapsulating other polymers (biodegradable or non-biodegradable) entities into the algal blends of thermoplastic nature. Equivalently, employing wastewater as a nutrient substrate for algae-based plastic production has also resulted in a beneficial strategy for synthesizing biodegradable bioplastics in an economically efficient manner. Indeed, carrying out concurrent research while considering algae as a promising and harmless bioplastic candidate can aid in diminishing the dependency on fossil fuels, improving the quality of plastic produced, and 
can help in minimizing the negative impact of petroleum plastics on the environment.

\section{Scale-Up and Downstream Processing of Microbial Bioplastic in Pure Cultures}

Although microbial community has been determined as a proficient candidature for bioplastic production; however, just optimizing the growth and accumulation of bioplastic precursors at lab. Scale is not sufficient enough for commercialization of bioplastic material. Scaling up of lab-scale parameters on pilot scale have frequently let down, reason being the added factors related to type of pilot-scale plant. Pilot-scale plant includes two categories: closed bioreactors and open pond systems.

Closed bioreactors are often utilized for upscaling axenic cultures. It is easy to maintain purity and controlled conditions in closed reactors, but additional costs to operate the reactor have a negative impact on the cost of final product (Alam et al., 2020). Another factor adding to the cost is substrate. Using pure substrate at pilot scale is not feasible from an economic point of view. To overcome these factors, many studies have performed and introduced various cheap substrates for PHA production (Bhagat et al., 2020; Riedel and Brigham, 2020). Operational conditions like agitation, and aeration impacts growth as well as PHA accumulation inside the reactor. Halomonas campisalis MCMB-1027 was grown in a $14 \mathrm{~L}$ reactor and accumulated $41 \%$ PHA under optimum agitation and aeration. Optimized dissolved oxygen level (DO) further increased accumulation up to $56 \%$. This optimization helped developing a correlation for upscaling up to $120 \mathrm{~L}$ fermentor (Kshirsagar et al., 2013). Optimizing all the operational conditions can be time consuming, model-based approaches can resolve limitations (Papapostolou et al., 2019). Closed photobioreactors are often used for photosynthetic microorganisms. Flue gases can be used as a substrate to trigger PHA accumulation (Troschl et al., 2017). A semi-continuous tubular photobioreactor was used to grow Synechocystis sp. CCALA192, $\mathrm{CO}_{2}$ was used as substrate, and $12.5 \%$ PHB was accumulated in the semicontinuous mode (Troschl et al., 2018). Byproducts like glycerol, grape pomace, and molasses can also serve the purpose (Nighat Naheed, 2012; Follonier et al., 2015; Volova et al., 2019).

High-rate algal ponds often used to grow microalgae, utilizes waste water as substrate (Chakravarty et al., 2010; Simon et al., 2016; Abdo and Ali, 2019). It has a low operational cost as compared to closed reactors but maintaining axenic cultures is tough task, especially when wastewater has high COD and VFA content. Scaling up mixed culture is far better due to low maintenance and wide range availability of substrate choices and in tailor-made consortium, microorganisms based on their attributes and compatibility can be selected for soaring PHA production.

Even pilot-scale production of PHB accumulated within the cyanobacteria has been known to be difficult due to the contamination-related challenges which eventually hinder the purity of the type of bioplastic produced (Troschl et al., 2018). It has been postulated that a distinct strategy needs to be devised for large-scale cultivation of bioplastic. Thus, while optimizing upstream processing steps at lab-scale, pilotscale approach should also be looked into extensively, followed by the investigation of appropriate extraction strategy. A sustainable bioplastic purification process that is cost-effective has a lower impact on the environment and higher conversion efficiency as compared to the traditional methodology. As the cost of different steps of bioplastic downstream processing elevates the overall bioplastic manufacturing cost; therefore, detailed scrutinization of different types of extraction and purification techniques taking part in the process should be taken into account for facilitating commercialization of bio-based plastics.

Downstream processing has also been known to contribute substantially in determining the economic status of bioplastic production owing to high accumulation of PHA inside the cell and lower yield of product extracted; therefore, different extraction and purification strategies also need to be investigated to make the process economically feasible and environmentally sustainable (Lorini et al., 2021).

While extracting and purifying bioplastic precursors from the microbe, several factors need to be considered for discerning the strategy to be adopted for economical downstream processing. Parameters, such as type of PHA-producing microbe, yield, and type of bioplastic, and the purity of the product to be extracted help in deciding the extraction procedure. Eventually, the extraction and purification methodology employed not only influences the type of bioplastic material produced but also delineates the environmental and economical consideration of the same (Koller et al., 2013).

A comparative analysis of various strategies available for PHA extraction has been done by Kurian and Das, 2021. In the following study, they have mentioned chemical and biological extraction processes and concluded biological process is better than the chemical approach. In another study with a similar aim suggested choosing extraction process on the basis of end product (Kunasundari and Sudesh, 2011).

Additionally, LCA and techno-economic analysis of various PHA recovery processes have been performed and illustrated that the usage of solvent leads to a hike in the production cost of bioplastic and should be persuaded only while employing solvents obtained from biorefinery setup or should be performed when absolute form of bioplastic precursor is required. Likewise, economical and environmental impact of every methodology involved in the downstream processing of bioplastic precursors needs to be exercised for attaining sustainable bioplastic production design (del Oso et al., 2021).

\section{THE QUINTESSENCE OF MIXED MICROBIAL CULTURE IN BIOPLASTIC PRODUCTION}

The utilization of pure microbial cultures for improved PHA production requires the supplementation of costly co-factors, vitamins, and organic substrates to strengthen the microbial metabolic processes, accompanied by the strict process control 
framework initiated by sterilization of equipment and growth media. All these parameters and requirements add-on to bioplastic production cost, thus obliterating the commercialization of bio-based plastic. In order to overcome these economical and technical hurdles, the administration of MMCs or photosynthetic microbial cultures (PMC) for the production of building blocks of bioplastic, such as Polyhydroxybutyrate or polyhydroxyvalerate, has been proposed. The MMC utilization caters to the reduced bioplastic production cost owing to the consumption of inexpensive heterogeneous feedstocks complemented with the open cultivation conditions, neglecting the need for sterilization or stringent control regulations. Volatile fatty acids including, butyrate, propionate, acetate, and valerate obtained from the fermentation of sewage streams are known to be the best precursors utilized by MMCs for PHA production (Albuquerque et al., 2011). Certainly, the financial supremacy and significance of MMCs over pure cultures for PHA production have also been illustrated by the comparative financial analysis and LCA of MMC's PHA production (Gurieff and Lant, 2007). Nevertheless, apart from the economic outlook, wastewater or sewage stream usage as an alternative to the nutrient substrate by MMC's along with the production of biodegradable plastic has contributed to the diminished environmental footprint of bioplastic production.

However, to generate an elevated amount of PHA, the microbial genera present in the MMC needs to be specified and optimized. For the selection of microbes, the culture has been transiently fed by obeying the feast and famine regime, which comprises of an intermittent feeding strategy, delineated as the enrichment of the culture with external carbon substrate (Feast) for a particular period of time, followed by the depletion of the carbon substrate (Famine) in the alternative time period. These feast and famine cycles are repeatedly practiced, which favors cell growth, as well as accumulation of storage molecules, such as PHA during the feast cycle and later gets consumed during the famine cycle. Thus, microorganisms having high PHA storage capacity will ultimately survive and grow, becoming the microorganism of choice for inclusion in the MMCs (Dionisi et al., 2006; Serafim et al., 2006; Albuquerque et al., 2007, 2010a,b; Oliveira et al., 2017).

Furthermore, the operating conditions and the composition of the substrate also play a significant role in the selection of diverse microbial species (Jiang et al., 2011a,b,c). Different researchers have worked on the varied substrate preferences of these organisms as presented in Table 3, which provide significant knowledge that might be used further to optimize PHA accumulation by tweaking the microbial community's assembly (Jiang et al., 2011a; Albuquerque et al., 2013; Marang et al., 2013; Pardelha et al., 2013; Carvalho et al., 2014). Subsequently, the system's operating parameters, including $\mathrm{pH}$, temperature, feeding strategy, sludge retention time, a feast to famine ratio, and organic loading rate, have also been observed to significantly affect the PHA composition and content by influencing the culture conditions of MMC (Dionisi et al., 2006; Johnson et al., 2009, 2010; Villano et al., 2010; Albuquerque et al., 2011; Jiang et al., 2011c; Chen et al., 2013; Wang et al., 2013; Carvalho et al., 2014).
TABLE 3 | PHA accumulation by MMCs under the supplementation of varying substrates.

\begin{tabular}{|c|c|c|c|}
\hline Substrate & $\begin{array}{l}\text { Bioplastic } \\
\text { monomer }\end{array}$ & $\begin{array}{l}\text { PHA } \\
\text { Accumulation } \\
(\% D C W)^{\#}\end{array}$ & References \\
\hline Crude Glycerol & PHB & $49-60 \%$ dcw & $\begin{array}{l}\text { Dobroth et al., } \\
2011\end{array}$ \\
\hline $\begin{array}{l}\text { Fermented Dairy } \\
\text { Manure }\end{array}$ & $\mathrm{P}(3-\mathrm{HB}-\mathrm{CO}-3-\mathrm{HV})$ & $22.5-90.7 \%$ dcw & Coats et al., 2016 \\
\hline $\begin{array}{l}\text { Fermented cheese } \\
\text { whey with acetate } \\
\text { pulse }\end{array}$ & P(3-HB-co-3-HV) & $30 \%$ NSS & $\begin{array}{l}\text { Fradinho et al., } \\
2019\end{array}$ \\
\hline $\begin{array}{l}\text { Acidified hardwood } \\
\text { spent sulfite liquor }\end{array}$ & $\mathrm{P}(3-\mathrm{HB}-\mathrm{CO}-3-\mathrm{HV})$ & $44.5 \%$ dcw & Pereira et al., 2020 \\
\hline Volatile Fatty acid & $\mathrm{P}(3-\mathrm{HB}-\mathrm{CO}-3-\mathrm{HV})$ & $44 \%$ dcw & $\begin{array}{l}\text { Guerra-Blanco } \\
\text { et al., } 2018\end{array}$ \\
\hline Sucrose & $\mathrm{P}(3-\mathrm{HB}-\mathrm{Co}-3-\mathrm{HV})$ & $23.8 \mathrm{mg} / \mathrm{L} / \mathrm{Day}$ & Löwe et al., 2017 \\
\hline $\begin{array}{l}\text { Fermented } \\
\text { Domestic } \\
\text { Wastewater }\end{array}$ & P(3-HB-co-3-HV) & $30.8 \%$ NSS & $\begin{array}{l}\text { Almeida et al., } \\
2021\end{array}$ \\
\hline
\end{tabular}

\#\%DCW $=\%$ Dry Cell Weight.

$P H B=$ Polyhydroxybutyrate, $V S S=$ Volatile suspended solids; and $P(3 H B-c 0-3 H V)=$ poly(3-hydroxybutyrate-co-3-hydroxy valerate).

As per the aforementioned literature, besides bacteria, algae have also been in the league of PHA production. Based on aforementioned facts, the algae-bacteria consortiums have been ascertained and reported to have the potential for wastewater treatment accompanied by the production of different biotechnologically essential bioenergy products (Ogbonna et al., 2000; Safonova et al., 2004; Van Iersel, 2009; Perez-Garcia et al., 2011).

According to the literature study done, the highest energyintensive prerequisite of MMCs recognized is the supply of proper aeration for fulfilling the requirement of oxygen (an electron acceptor) because the PHA content accumulated in an aerobic environment (75\%) is substantially high as compared to the PHA content gathered in anaerobic/aerobic environment (37\%). However, the requirement of aeration ultimately increases the operation cost involved in the PHA production by MMCs (Dionisi et al., 2004; Dai et al., 2007; Rosso et al., 2008; Bengtsson, 2009; Albuquerque et al., 2010b).

While looking into the PHA production efficiency of pure bacterial species and mixed microbial consortia, an example of Ralstonia eutropha can be considered. $R$. eutropha independently under the supplementation of VFAs derived from food waste is known to accumulate approximately $52 \%$ PHA copolymer (Bhatia et al., 2019). Although R. eutropha cannot assimilate sucrose in the form of carbon sources, however when synthetic mixed microbial consortia composed of Bacillus subtilis and $R$. eutropha is grown in the presence of sugarcane sugar then it leads to the accumulation of about 66\% PHA copolymer. Therefore, it suggests the importance of MMCs over the pure bacterial culture for the purpose of PHA production (Bhatia et al., 2018). The biosynthesis of PHB by MMC supplemented with the crude glycerol (obtained as a byproduct from the production of biodiesel) was evaluated by a group 
of scientists and illustrated that due to the deficiency of macronutrients in the presence of crude glycerol, accumulation of $\mathrm{PHB}$ is elated. They projected that on scaling up, about 20.9 tons of PHB could be produced every year by MMCs while processing 10 million gallons of biodiesel every year (Dobroth et al., 2011).

Therefore, to vanquish this obligation, Fradinho et al. (2013a) culminated the enrichment of photosynthetic mixed culture comprising of bacteria and algae consortia by observing the accumulation of PHA by bacteria in the feast cycle followed by its consumption in the famine cycle while using the oxygen generated by the photosynthetic algae, thus excluding the need of aeration provided externally. The PHA accumulated by algaebacteria consortia was reported to be $20 \%$ PHA per volatile suspended solid (VSS) when the culture was supplemented with acetate in the form of a carbon source.

It has been proven by the previous studies that oxidation of reducing molecules like NADP and NADPH is required for conversion of carbon source into PHA. In the absence of oxygen, these reducing molecules will never be oxidized, and carbon source conversion to PHA will not be initiated. Hence, justifying the quintessence of photosynthetically mixed culture (composed of algae and bacteria consortia) for ameliorated polyhydroxyalkanoate production (PHA; Fradinho et al., 2013a,b, 2014, 2016).

Weiss et al. too designed a synthetic consortium comprising of a photoautotroph and a chemoautotroph. The synthetic consortia were light-driven, and the heterotrophic Halomonas boliviensis bacterium was capable of metabolizing sucrose secreted by algae, Synechococcus elongatus CscB. It was reported that the bacteria in consortia were able to accumulate about $31 \%$ dry cell weight of $\mathrm{PHB}$, with the productivity of $28.3 \mathrm{mg}$ PHB L ${ }^{-1} D^{-1}$ (Kourmentza et al., 2017; Weiss et al., 2017). In a nutshell, an upcoming paradigm of embracing the importance of MMCs for the production of bioplastic, especially PHA, should be practiced to ensure sustainable and economically feasible bioplastic production on a commercial scale (Figure 2).

On summarizing the positive impact of photoautotrophic cultivation of algae, i.e., no specific requirement of agricultural land, high $\mathrm{CO}_{2}$ sequestration ability, photosynthetic efficiency, and treatment of waste material prove to be economically proficient over the heterotrophic growth of bacteria. However, even the maintaining axenic cultures of algae on a large scale has been known to be economically infeasible due to maintenance cost of the optimal physico-chemical parameters for the production of PHA. Therefore, to overcome all the challenges discussed previously, MMCs composed of either different chemoautotrophic bacteria or that of algae and phototrophic bacteria need to be practiced and explored further for making the PHA production process economically feasible. Not only different microbes participating in the mixed consortia need to be investigated for their PHA yield but varying physical and chemical parameters affecting the accumulation capability of the consortia also need to be optimized for obtaining supreme yield keeping in view the large-scale production of bioplastic.

\section{EXISTING COMMERCIAL STATUS QUO OF BIOPLASTICS}

The global upsurge and advancement in the bioplastic market are attributed to its sustainable production protocol (compared to conventional plastic) and its widespread applications in different industrial fields, such as food services and packaging. Moreover, increasing awareness regarding the benefits of biocompatible and biodegradable plastic, formulation of government norms to stimulate and acknowledge eco-friendly techniques, and ever-augmenting fossil-fuel prices have invigorated the commercial diversion toward the production of bioplastic elements.

The worldwide spread of bioplastic business is still subordinate as compared to the petroleum-based plastic market. Different bioplastic-producing plants are situated in different parts of the world, including Italy, Brazil, the United States, China, and others. Indeed, various industries are in the business of bioplastic production, especially PHA thermoplastic material.

It has been evident that microalgae have proved to be a superlative candidate for the production of bioplastic but needs to be explored further in order to achieve commercial production of bioplastic emanated from microalgae independently or in consortium with bacteria. A substitute for a plastic bottle was also prepared by the composition of red algae powder and water (Verlinden et al., 2007; Singh et al., 2017; Alcântara et al., 2020; Chia et al., 2020; Price et al., 2020; Shafqat et al., 2020). Therefore, commercialization of bioplastic emanated from algae can be achieved by investigating the bioplastic production potential of various algal species along with the metabolic engineering and evaluation of multiple aspects influencing the accumulation of bioplastics. However, acquiring a more profound understanding of the know-how related to downstream processing as well as the participation of algae-derived plastics need to be the prime concern of the researchers, as they contribute considerably to the production cost of commercialized plastic.

\section{CONCLUDING REMARKS}

Microbes are scrutinized substantially for the synthesis of sustainable bioplastics and had proven to be a magnificent source of bioplastic precursors that could be utilized further to produce biocompatible and carbon-neutral biodegradable products. As per literature, bacteria have been reported to accumulate about $80-90 \%$ of PHA when subjected to optimal conditions. Currently, bacteria are consistently exploited to commercialize biodegradable and sustainable bacterial bioplastic, and many industries are doing business out of it. Despite bioplastic production via bacteria being commercialized, a cost-effective, sustainable large-scale venture for the synthesis of bioplastic, especially PHA bioplastic, is still in its early years. The challenges faced in the process include the need for expensive carbon sources, operational cost to maintain the process control parameters, low yield 


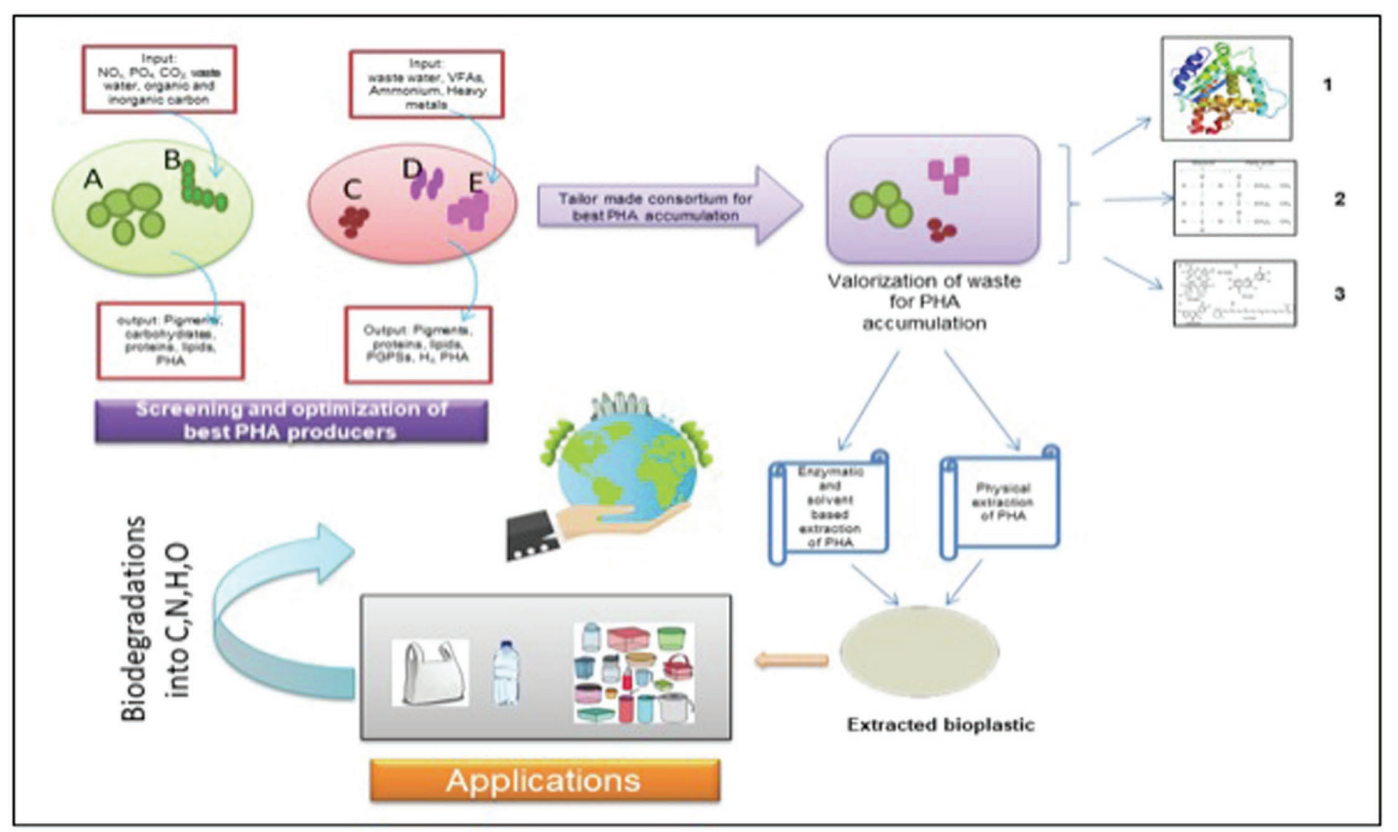

FIGURE 2 | An illustrative biorefinery approach for tailor-made consortium of photosynthetic microorganisms. Microalgae; B- Filamentous Cyanobacteria; C- Photosynthetic bacteria 1; D- Photosynthetic bacteria; and E- Photosynthetic bacteria. 1. Protein; 2. Triacylglycerides, and 3. Pigments. NO ${ }_{x}$ Nitrates, PO 4 Phosphate, $\mathrm{CO}_{2}$ : Carbon dioxide; VFAs: Volatile fatty acids; PGPSs: Plant growth promoting substances; $\mathrm{H}_{2}$ : Hydrogen; PHA: Polyhydroxyalkanoates; C:Carbon; $\mathrm{N}$ : Nitrogen; H: Hydrogen; and O: Oxygen.

of a metabolite of interest, difficulty in achieving considerable productivity, and downstream processing steps. Whereas, usage photosynthetic organisms are still in their early course nut they have immense leeway for achieving a greater place in bioplastic industries. From the past few decades, microalgae and cyanobacteria are also under surveillance for evaluating their potential of bioplastic precursor accumulation or for direct usage in bioplastic production. Nevertheless, the methodologies evolved for the production of algal bioplastic are not economically feasible and environmentally sustainable. Additionally, many technical and procedural complications occur while scaling up bioplastic production emanated from algae.

Keeping in mind the various pro and cons of $\mathrm{PHA}$ production via various microbes individually, a consortium approach seems to be a light in the dusk. In recent years, different MMCs are under observation to uncover their bioplastic production potential, either by tweaking certain culture conditions or by metabolic engineering approach. The practice of utilizing photosynthetic MMCs composed of bacteria and algae consortia or different photosynthetic bacteria, accompanied by the consumption of wastewater or byproducts of various production processes like molasses, grape pomace, olive pomace, and crude glycerol as a substitute for pure organic carbon source, will prove to be an efficacious perspective for the production of economically feasible, environmentally sustainable, and biodegradable bioplastic. PHA produced by MMCs can also have a greater composition for a better composition and mechanical properties.
A biorefinery approach can also help overcome the cost and sustainability crisis in commercialization of PHA as bioplastic. Tailor-made consortium of microalgae and photosynthetic bacteria will attain high productivity of PHA as well as precursors of bioenergy molecules to spread out the burden of scaling up. In a nutshell, promising biodegradable bioplastic constituents can be derived from algae and bacterial consortia as an alternative for replacing traditional fossil-based plastics, ultimately unraveling the strategy of reducing plastic pollution as well as the burden on the finite resources.

\section{AUTHOR CONTRIBUTIONS}

KS worked on conceptualization, methodology, and visualization. RS gave her contribution in data curation and writing the original draft. $\mathrm{RN}$ reviewed and edited the manuscript. KB supervised and conceived the manuscript. Manuscript was critically reviewed and approved by all the authors.

\section{ACKNOWLEDGMENTS}

The authors are thankful to DAAD for the LUH-IITI mobility grant and IIT Indore for providing the necessary support. KS is thankful to MHRD, India, and RS is thankful to UGC, India, for fellowship support. The funding agency has not played any role in the design or decisions regarding the publication of a manuscript. 


\section{REFERENCES}

Abdo, S. M., and Ali, G. H. (2019). Analysis of polyhydroxybutrate and bioplastic production from microalgae. Bull. Natl. Res. Cent. 43, 1-4. doi: 10.1186/ s42269-019-0135-5

Abdul-Latif, N.-I. S., Ong, M. Y., Nomanbhay, S., Salman, B., and Show, P. L. (2020). Estimation of carbon dioxide (CO2) reduction by utilization of algal biomass bioplastic in Malaysia using carbon emission pinch analysis (CEPA). Bioengineered 11, 154-164. doi: 10.1080/21655979.2020.1718471

Abiusi, F., Wijffels, R. H., and Janssen, M. (2020). Doubling of microalgae productivity by oxygen balanced mixotrophy. ACS Sustain. Chem. Eng. 8, 6065-6074. doi: 10.1021/acssuschemeng.0c00990

Adane, L., and Muleta, D. (2011). Survey on the usage of plastic bags, their disposal and adverse impacts on environment: A case study in Jimma City, southwestern Ethiopia. J. Toxicol. Environ. Heal. Sci. 3, 234-248. doi: 10.5897/ JTEHS.9000067

Alam, M. A., Xu, J. L., and Wang, Z. (2020). Microalgae Biotechnology for Food, Health and High Value Products. Germany: Springer.

Albuquerque, M. G. E., Carvalho, G., Kragelund, C., Silva, A. F., Crespo, M. T. B., Reis, M. A. M., et al. (2013). Link between microbial composition and carbon substrate-uptake preferences in a PHA-storing community. ISME J. 7, 1-12. doi: 10.1038/ismej.2012.74

Albuquerque, M. G. E., Concas, S., Bengtsson, S., and Reis, M. A. M. (2010a). Mixed culture polyhydroxyalkanoates production from sugar molasses: the use of a 2-stage CSTR system for culture selection. Bioresour. Technol. 101, 7112-7122. doi: 10.1016/j.biortech.2010.04.019

Albuquerque, M. G. E., Eiroa, M., Torres, C., Nunes, B. R., and Reis, M. A. M. (2007). Strategies for the development of a side stream process for polyhydroxyalkanoate (PHA) production from sugar cane molasses. J. Biotechnol. 130, 411-421. doi: 10.1016/j.jbiotec.2007.05.011

Albuquerque, M. G. E., Martino, V., Pollet, E., Avérous, L., and Reis, M. A. M. (2011). Mixed culture polyhydroxyalkanoate (PHA) production from volatile fatty acid (VFA)-rich streams: effect of substrate composition and feeding regime on PHA productivity, composition and properties. J. Biotechnol. 151, 66-76. doi: 10.1016/j.jbiotec.2010.10.070

Albuquerque, M. G. E., Torres, C. A. V., and Reis, M. A. M. (2010b). Polyhydroxyalkanoate (PHA) production by a mixed microbial culture using sugar molasses: effect of the influent substrate concentration on culture selection. Water Res. 44, 3419-3433. doi: 10.1016/j.watres.2010.03.021

Alcântara, J. M. G., Distante, F., Storti, G., Moscatelli, D., Morbidelli, M., and Sponchioni, M. (2020). Current trends in the production of biodegradable bioplastics: The case of polyhydroxyalkanoates. Biotechnol. Adv. 42:107582. doi: 10.1016/j.biotechadv.2020.107582

Aldor, I. S., and Keasling, J. D. (2003). Process design for microbial plastic factories: metabolic engineering of polyhydroxyalkanoates. Curr. Opin. Biotechnol. 14, 475-483. doi: 10.1016/j.copbio.2003.09.002

Allegue, L. D., Ventura, M., Melero, J. A., and Puyol, D. (2021). Integrated sustainable process for polyhydroxyalkanoates production from lignocellulosic waste by purple phototrophic bacteria. GCB Bioenergy 13, 862-875. doi: $10.1111 /$ gcbb. 12807

Alloul, A., Wuyts, S., Lebeer, S., and Vlaeminck, S. E. (2019). Volatile fatty acids impacting phototrophic growth kinetics of purple bacteria: paving the way for protein production on fermented wastewater. Water Res. 152, 138-147. doi: 10.1016/j.watres.2018.12.025

Almeida, J. R., Serrano, E., Fernandez, M., Fradinho, J. C., Oehmen, A., and Reis, M. A. M. (2021). Polyhydroxyalkanoates production from fermented domestic wastewater using phototrophic mixed cultures. Water Res. 197:117101. doi: 10.1016/j.watres.2021.117101

Amaro, T. M. M. M., Rosa, D., Comi, G., and Iacumin, L. (2019). Prospects for the use of whey for polyhydroxyalkanoate (PHA) production. Front. Microbiol. 10, 1-12. doi: 10.3389/fmicb.2019.00992

Anand, V., Kashyap, M., Samadhiya, K., Ghosh, A., and Kiran, B. (2019). Salinity driven stress to enhance lipid production in Scenedesmus vacuolatus: A biodiesel trigger? Biomass Bioenergy 127:105252. doi: 10.1016/j. biombioe.2019.05.021

Anderson, A. J., and Dawes, E. A. (1990). Occurrence, metabolism, metabolic role, and industrial uses of bacterial polyhydroxyalkanoates. Microbiol. Mol. Biol. Rev. 54, 450-472. doi: 10.1128/mr.54.4.450-472.1990
Anjum, S., Arora, A., Alam, M. S., and Gupta, B. (2016). Development of antimicrobial and scar preventive chitosan hydrogel wound dressings. Int. J. Pharm. 508, 92-101. doi: 10.1016/j.ijpharm.2016.05.013

Arun, J., Gopinath, K. P., SundarRajan, P., Felix, V., JoselynMonica, M., and Malolan, R. (2020). A conceptual review on microalgae biorefinery through thermochemical and biological pathways: bio-circular approach on carbon capture and wastewater treatment. Bioresour. Technol. Reports 11:100477. doi: 10.1016/j.biteb.2020.100477

Babu, R. P., O'connor, K., and Seeram, R. (2013). Current progress on biobased polymers and their future trends. Prog. Biomater. 2, 1-16. doi: 10.1186/2194-0517-2-8

Batcha, A. F. M., Prasad, D. M. R., Khan, M. R., and Abdullah, H. (2014). Biosynthesis of poly(3-hydroxybutyrate) (PHB) by Cupriavidus necator H16 from jatropha oil as carbon source. Bioprocess Biosyst. Eng. 37, 943-951. doi: 10.1007/s00449-013-1066-4

Bayon-Vicente, G., Zarbo, S., Deutschbauer, A., Wattiez, R., and Leroy, B. (2020). Photoheterotrophic assimilation of valerate and associated polyhydroxyalkanoate production by Rhodospirillum rubrum. Appl. Environ. Microbiol. 86:e00901-20. doi: 10.1128/AEM.00901-20

Beacham, T. A., Sweet, J. B., and Allen, M. J. (2017). Large scale cultivation of genetically modified microalgae: A new era for environmental risk assessment. Algal Res. 25, 90-100. doi: 10.1016/j.algal.2017.04.028

Beckstrom, B. D., Wilson, M. H., Crocker, M., and Quinn, J. C. (2020). Bioplastic feedstock production from microalgae with fuel co-products: A technoeconomic and life cycle impact assessment. Algal Res. 46:101769. doi: 10.1016/j. algal.2019.101769

Bengtsson, S. (2009). The utilization of glycogen accumulating organisms for mixed culture production of polyhydroxyalkanoates. Biotechnol. Bioeng. 104, 698-708. doi: 10.1002/bit.22444

Bhagat, N. R., Kumari, P., Giri, A., and Gahlawat, G. (2020). "The sustainable production of Polyhydroxyalkanoates from crude glycerol," in The Handbook of Polyhydroxyalkanoates (United States: CRC Press), 222-256.

Bhati, R., and Mallick, N. (2012). Production and characterization of poly(3hydroxybutyrate-co-3-hydroxyvalerate) co-polymer by a N 2-fixing cyanobacterium, Nostoc muscorum Agardh. J. Chem. Technol. Biotechnol. 87, 505-512. doi: $10.1002 /$ jctb. 2737

Bhati, R., and Mallick, N. (2015). Poly(3-hydroxybutyrate-co-3-hydroxyvalerate) copolymer production by the diazotrophic cyanobacterium Nostoc muscorum Agardh: process optimization and polymer characterization. Algal Res. 7, 78-85. doi: 10.1016/j.algal.2014.12.003

Bhatia, S. K., Gurav, R., Choi, T. R., Jung, H. R., Yang, S. Y., Song, H. S., et al. (2019). Poly (3-hydroxybutyrate-co-3-hydroxyhexanoate) production from engineered Ralstonia eutropha using synthetic and anaerobically digested food waste derived volatile fatty acids. Int. J. Biol. Macromol. 133, 1-10. doi: 10.1016/j.ijbiomac.2019.04.083

Bhatia, S. K., Yoon, J. J., Kim, H. J., Hong, J. W., Hong, Y. G., Song, H. S., et al. (2018). Engineering of artificial microbial consortia of Ralstonia eutropha and Bacillus subtilis for poly (3-hydroxybutyrate-co-3hydroxyvalerate) copolymer production from sugarcane sugar without precursor feeding. Bioresour. Technol. 257, 92-101. doi: 10.1016/j.biortech. 2018.02.056

Bio-on (2021). Available at: http://www.bio-on.it/index.php (Accessed February, 2021).

Brandl, H., Gross, R. A., Lenz, R. W., and Fuller, R. C. (1988). Pseudomonas oleovorans as a source of poly ( $\beta$-hydroxyalkanoates) for potential applications as biodegradable polyesters. Appl. Environ. Microbiol. 54, 1977-1982. doi: 10.1128/aem.54.8.1977-1982.1988

Braunegg, G., Lefebvre, G., and Genser, K. F. (1998). Polyhydroxyalkanoates, biopolyesters from renewable resources: physiological and engineering aspects. J. Biotechnol. 65, 127-161. doi: 10.1016/S0168-1656(98)00126-6

Broeren, M. L. M., Kuling, L., Worrell, E., and Shen, L. (2017). Environmental impact assessment of six starch plastics focusing on wastewater-derived starch and additives. Resour. Conserv. Recycl. 127, 246-255. doi: 10.1016/j. resconrec.2017.09.001

Budde, C. F., Riedel, S. L., Hübner, F., Risch, S., Popović, M. K., Rha, C., et al. (2011). Growth and polyhydroxybutyrate production by Ralstonia eutropha in emulsified plant oil medium. Appl. Microbiol. Biotechnol. 89, 1611-1619. doi: 10.1007/s00253-011-3102-0 
Byrom, D. (1992). Production of poly- $\beta$-hydroxybutyrate: poly- $\beta$-hydroxyvalerate copolymers. FEMS Microbiol. Rev. 9, 247-250. doi: 10.1111/j.1574-6968.1992. tb05844.x

Byrom, D. (1994). Plastics From Microbes: Microbial Synthesis of Polymers and Polymer Precursors. Munich: Hanser, 5-33.

Carlozzi, P., Seggiani, M., Capperucci, A., Tanini, D., Cinelli, P., and Lazzeri, A. (2019). Hydroxytyrosol rich-mixture from olive mill wastewater and production of green products by feeding Rhodopseudomonas sp. S16FVPT5 with the residual effluent. J. Biotechnol. 295, 28-36. doi: 10.1016/j. jbiotec.2019.02.006

Carvalho, G., Oehmen, A., Albuquerque, M. G. E., and Reis, M. A. M. (2014). The relationship between mixed microbial culture composition and PHA production performance from fermented molasses. New Biotechnol. 31, 257-263. doi: 10.1016/j.nbt.2013.08.010

Cassuriaga, A. P. A., Freitas, B. C. B., Morais, M. G., and Costa, J. A. V. (2018). Innovative polyhydroxybutyrate production by Chlorella fusca grown with pentoses. Bioresour. Technol. 265, 456-463. doi: 10.1016/j. biortech.2018.06.026

Cea-Barcia, G., Buitrón, G., Moreno, G., and Kumar, G. (2014). A cost-effective strategy for the bio-prospecting of mixed microalgae with high carbohydrate content: diversity fluctuations in different growth media. Bioresour. Technol. 163, 370-373. doi: 10.1016/j.biortech.2014.04.079

Chakravarty, P., Mhaisalkar, V., and Chakrabarti, T. (2010). Bioresource technology study on poly-hydroxyalkanoate (PHA) production in pilot scale continuous mode wastewater treatment system. Bioresour. Technol. 101, 2896-2899. doi: 10.1016/j.biortech.2009.11.097

Chalima, A., Oliver, L., De Castro, L. F., Karnaouri, A., Dietrich, T., and Topakas, E. (2017). Utilization of volatile fatty acids from microalgae for the production of high added value compounds. Fermentation 3, 1-17. doi: $10.3390 /$ fermentation 3040054

Chandani, N., Mazumder, P. B., and Bhattacharjee, A. (2014). Production of polyhydroxybutyrate (biopolymer) by bacillus tequilensis NCS-3 isolated from municipal waste areas of Silchar. Assam. Int. J. Sci. Res 3, 198-203.

Chandra, R., Iqbal, H. M. N., Vishal, G., Lee, H.-S., and Nagra, S. (2019). Algal biorefinery: a sustainable approach to valorize algal-based biomass towards multiple product recovery. Bioresour. Technol. 278, 346-359. doi: 10.1016/j.biortech.2019.01.104

Chaogang, W., Zhangli, H., Anping, L., and Baohui, J. (2010). Biosynthesis of poly-3-hydroxybutyrate (phb) in the transgenic green alga chlamydomonas reinhardtii 1. J. Phycol. 46, 396-402. doi: 10.1111/j.1529-8817.2009.00789.x

Chaudhry, W. N., Jamil, N., Ali, I., Ayaz, M. H., and Hasnain, S. (2011). Screening for polyhydroxyalkanoate (PHA)-producing bacterial strains and comparison of PHA production from various inexpensive carbon sources. Ann. Microbiol. 61, 623-629. doi: 10.1007/s13213-010-0181-6

Chen, Y., Awasthi, A. K., Wei, F., Tan, Q., and Li, J. (2020). Single-use plastics: production, usage, disposal, and adverse impacts. Sci. Total Environ. 752:141772. doi: $10.1016 /$ j.scitotenv.2020.141772

Chen, G.-Q., and Jiang, X.-R. (2018). Engineering microorganisms for improving polyhydroxyalkanoate biosynthesis. Curr. Opin. Biotechnol. 53, 20-25. doi: 10.1016/j.copbio.2017.10.008

Chen, H., Meng, H., Nie, Z., and Zhang, M. (2013). Polyhydroxyalkanoate production from fermented volatile fatty acids: effect of $\mathrm{pH}$ and feeding regimes. Bioresour. Technol. 128, 533-538. doi: 10.1016/j.biortech.2012.10.121

Chia, W. Y., Tang, D. Y. Y., Khoo, K. S., Lup, A. N. K., and Chew, K. W. (2020). Nature's fight against plastic pollution: algae for plastic biodegradation and bioplastics production. Environ. Sci. Ecotechnol. 4:100065. doi: 10.1016/j. ese. 2020.100065

Chiellini, E., Cinelli, P., Ilieva, V. I., and Martera, M. (2008). Biodegradable thermoplastic composites based on polyvinyl alcohol and algae. Biomacromolecules 9, 1007-1013. doi: 10.1021/bm701041e

Ciesielski, S., Możejko, J., and Przybyłek, G. (2010). The influence of nitrogen limitation on mcl-PHA synthesis by two newly isolated strains of pseudomonas sp. J. Ind. Microbiol. Biotechnol. 37, 511-520. doi: 10.1007/s10295-010-0698-5

Coats, E. R., Watson, B. S., and Brinkman, C. K. (2016). Polyhydroxyalkanoate synthesis by mixed microbial consortia cultured on fermented dairy manure: effect of aeration on process rates/yields and the associated microbial ecology. Water Res. 106, 26-40. doi: 10.1016/j.watres.2016.09.039

Colombo, B., Favini, F., Scaglia, B., Sciarria, T. P., D’Imporzano, G., Pognani, M., et al. (2017). Enhanced polyhydroxyalkanoate (PHA) production from the organic fraction of municipal solid waste by using mixed microbial culture. Biotechnol. Biofuels 10, 1-15. doi: 10.1186/s13068-017-0888-8

Crocker, M., Zeller, A., Quinn, J., Quiroz Nuila, D., Beckstrom, B., Kesner, S., et al. (2020). CO2 to bioplastics: beneficial re-use of carbon emissions from coal-fired power plants using microalgae. University of Kentucky Research Foundation.

Dai, Y., Yuan, Z., Jack, K., and Keller, J. (2007). Production of targeted poly (3-hydroxyalkanoates) copolymers by glycogen accumulating organisms using acetate as sole carbon source. J. Biotechnol. 129, 489-497. doi: 10.1016/j. jbiotec.2007.01.036

Das, S. K., Sathish, A., and Stanley, J. (2018). Production of biofuel and bioplastic from Chlorella pyrenoidosa. Mater. Today Proc. 5, 16774-16781. doi: 10.1016/j. matpr.2018.06.020

De Morais, M. G., and Costa, J. A. V. (2007). Carbon dioxide fixation by Chlorella kessleri, C. vulgaris, Scenedesmus obliquus and spirulina sp. cultivated in flasks and vertical tubular photobioreactors. Biotechnol. Lett. 29, 1349-1352. doi: 10.1007/s10529-007-9394-6

Debuissy, T., Pollet, E., and Avérous, L. (2018). Biotic and abiotic synthesis of renewable aliphatic polyesters from short building blocks obtained from biotechnology. ChemSusChem 11, 3836-3870. doi: 10.1002/ cssc. 201801700

del Oso, M. S., Mauricio-Iglesias, M., and Hospido, A. (2021). Evaluation and optimization of the environmental performance of PHA downstream processing. Chem. Eng. J. 412:127687. doi: 10.1016/j.cej.2020.127687

Dhangdhariya, J. H., Dubey, S., Trivedi, H. B., Pancha, I., Bhatt, J. K., Dave, B. P., et al. (2015). Polyhydroxyalkanoate from marine bacillus megaterium using CSMCRI's Dry Sea mix as a novel growth medium. Int. J. Biol. Macromol. 76, 254-261. doi: 10.1016/j.ijbiomac.2015.02.009

Di Caprio, F., Altimari, P., Iaquaniello, G., Toro, L., and Pagnanelli, F. (2019a), Heterotrophic cultivation of T. obliquus under non-axenic conditions by uncoupled supply of nitrogen and glucose. Biochem. Eng. J. 145, 127-136. doi: $10.1016 /$ j.bej.2019.02.020

Di Caprio, F., Altimari, P., and Pagnanelli, F. (2019b). "New strategies enhancing feasibility of microalgal cultivations," in Studies in Surface Science and Catalysis (United States: Elsevier), 287-316.

Dietrich, K., Dumont, M.-J., Del Rio, L. F., and Orsat, V. (2017). Producing PHAs in the bioeconomy - towards a sustainable bioplastic. Sustain. Prod. Consum. 9, 58-70. doi: 10.1016/j.spc.2016.09.001

Dionisi, D., Majone, M., Papa, V., and Beccari, M. (2004). Biodegradable polymers from organic acids by using activated sludge enriched by aerobic periodic feeding. Biotechnol. Bioeng. 85, 569-579. doi: 10.1002/bit.10910

Dionisi, D., Majone, M., Vallini, G., Di Gregorio, S., and Beccari, M. (2006). Effect of the applied organic load rate on biodegradable polymer production by mixed microbial cultures in a sequencing batch reactor. Biotechnol. Bioeng. 93, 76-88. doi: 10.1002/bit.20683

Dobroth, Z. T., Hu, S., Coats, E. R., and McDonald, A. G. (2011). Polyhydroxybutyrate synthesis on biodiesel wastewater using mixed microbial consortia. Bioresour. Technol. 102, 3352-3359. doi: 10.1016/j. biortech.2010.11.053

de Oliveira, G. H. D., Niz, M. Y. K., Zaiat, M., and Rodrigues, J. A. D. (2019). Effects of the Organic Loading Rate on Polyhydroxyalkanoate Production from Sugarcane Stillage by Mixed Microbial Cultures. Appl. Biochem. Biotechnol. 189, 1039-1055. doi: 10.1007/s12010-019-03051-9

Devasahayam, S., Bhaskar Raju, G., and Mustansar Hussain, C. (2019). Utilization and recycling of end of life plastics for sustainable and clean industrial processes including the iron and steel industry. Mater. Sci. Energy Technol. 2, 634-646. doi: 10.1016/j.mset.2019.08.002

Domínguez-Díaz, M., Meneses-Acosta, A., Romo-Uribe, A., Peña, C., Segura, D., and Espin, G. (2015). Thermo-mechanical properties, microstructure and biocompatibility in poly- $\beta$-hydroxybutyrates (PHB) produced by OP and OPN strains of Azotobacter vinelandii. Eur. Polym. J. 63, 101-112. doi: 10.1016/j.eurpolymj.2014.12.002

Elmarasi, M. (2017). Plastic bag bans: The future of shopping bags. Available at: http://urn.fi/URN:NBN:fi-fe2017110150467 (Accessed February 2021).

Favaro, L., Basaglia, M., and Casella, S. (2019). Improving polyhydroxyalkanoate production from inexpensive carbon sources by genetic approaches: a review. Biofuels. Bioprod. Biorefining 13, 208-227. doi: 10.1002/bbb.1944

Figols, B., Varrone, C., Daugaard, A., Skiadas, I., and Gavala, H. (2017). Enrichment strategies for Polyhydroxyalkanoates (PHA) production from 
fermented crude glycerol using mixed microbial cultures. Proc. 13th Renew. Resour. Biorefineries Conf. RRB-13; 7-9 June, 2017. Wroclaw, Poland.

Floccari, M. E., Lopez, N. I., Mendez, B. S., Furst, U. P., and Steinbuchel, A. (1995). Isolation and partial characterization of bacillus megaterium mutants deficient in poly(3-hydroxybutyrate) synthesis. Can. J. Microbiol. 41, 77-79. doi: $10.1139 / \mathrm{m} 95-172$

Follonier, S., Riesen, R., and Zinn, M. (2015). Pilot-scale Production of Functionalized mcl-PHA from Grape Pomace Supplemented with Fatty Acids. Chem. Biochem. Eng. Q. 29, 113-121. doi: 10.15255/CABEQ.2014.2251

Foong, C. P., Higuchi-Takeuchi, M., and Numata, K. (2019). Optimal iron concentrations for growth-associated polyhydroxyalkanoate biosynthesis in the marine photosynthetic purple bacterium Rhodovulum sulfidophilum under photoheterotrophic condition. PLoS One 14:e0212654. doi: 10.1371/ journal.pone. 0212654

Fradinho, J. C., Domingos, J. M. B., Carvalho, G., Oehmen, A., and Reis, M. A. M. (2013a). Polyhydroxyalkanoates production by a mixed photosynthetic consortium of bacteria and algae. Bioresour. Technol. 132, 146-153. doi: 10.1016/j.biortech.2013.01.050

Fradinho, J. C., Oehmen, A., and Reis, M. A. M. (2013b). Effect of dark/light periods on the polyhydroxyalkanoate production of a photosynthetic mixed culture. Bioresour. Technol. 148, 474-479. doi: 10.1016/j.biortech.2013.09.010

Fradinho, J. C., Oehmen, A., and Reis, M. A. M. (2014). Photosynthetic mixed culture polyhydroxyalkanoate (PHA) production from individual and mixed volatile fatty acids (VFAs): substrate preferences and co-substrate uptake. J. Biotechnol. 185, 19-27. doi: 10.1016/j.jbiotec.2014.05.035

Fradinho, J. C., Oehmen, A., and Reis, M. A. M. (2019). Improving polyhydroxyalkanoates production in phototrophic mixed cultures by optimizing accumulator reactor operating conditions. Int. J. Biol. Macromol. 126, 1085-1092. doi: 10.1016/j.ijbiomac.2018.12.270

Fradinho, J. C., Reis, M. A. M., and Oehmen, A. (2016). Beyond feast and famine: selecting a PHA accumulating photosynthetic mixed culture in a permanent feast regime. Water Res. 105, 421-428. doi: 10.1016/j. watres.2016.09.022

Gahlawat, G., and Srivastava, A. K. (2017). Model-based nutrient feeding strategies for the increased production of Polyhydroxybutyrate (PHB) by Alcaligenes latus. Appl. Biochem. Biotechnol. 183, 530-542. doi: 10.1007/ s12010-017-2482-8

García, B., Olivera, E. R., Miñambres, B., Fernández-Valverde, M., Cañedo, L. M., Prieto, M. A., et al. (1999). Novel biodegradable aromatic plastics from a bacterial source. Genetic and biochemical studies on a route of the phenylacetylCoA catabolon. J. Biol. Chem. 274, 29228-29241. doi: 10.1074/jbc.274.41. 29228

García, G., Sosa-Hernández, J. E., Rodas-Zuluaga, L. I., Castillo-Zacarías, C., Iqbal, H., and Parra-Saldívar, R. (2021). Accumulation of PHA in the microalgae Scenedesmus sp. under nutrient-deficient conditions. Polymers 13:131. doi: $10.3390 /$ polym 13010131

Giacovelli, C., and Zamparo, A. (2018) in Plastics: A Roadmap for Sustainability. ed. T. Cannon.

Ghosh, A., and Kiran, B. (2017). Carbon concentration in algae: reducing $\mathrm{CO} 2$ From exhaust gas. Trends Biotechnol. 35, 806-808. doi: 10.1016/j. tibtech.2017.05.003

Girotto, F., Alibardi, L., and Cossu, R. (2015). Food waste generation and industrial uses: a review. Waste Manag. 45, 32-41. doi: 10.1016/j. wasman.2015.06.008

Godfrey, L. (2019). Waste plastic, the challenge facing developing countriesban it, change it, collect it? Recycling 4:3. doi: 10.3390/recycling4010003

Gong, Y., and Huang, J. (2020). Characterization of four untapped microalgae for the production of lipids and carotenoids. Algal Res. 49:101897. doi: 10.1016/j.algal.2020.101897

Gonzalez-Gutierrez, J., Partal, P., Garcia-Morales, M., and Gallegos, C. (2010). Development of highly-transparent protein/starch-based bioplastics. Bioresour. Technol. 101, 2007-2013. doi: 10.1016/j.biortech.2009.10.025

Gopi, K. (2014). Isolation purification and screening of biodegradable polymer PHB producing cyanobacteria from marine and fresh water resources. Iran. J. Energy Environ. 5, 94-100. doi: 10.5829/idosi.ijee.2014.05.01.14

Green, P. R., Kemper, J., Schechtman, L., Guo, L., Satkowski, M., Fiedler, S., et al. (2002). Formation of short chain length/medium chain length polyhydroxyalkanoate copolymers by fatty acid $\beta$-oxidation inhibitedRalstonia eutropha. Biomacromolecules 3, 208-213. doi: 10.1021/bm015620m
Gualtieri, P. (2001). Morphology of photoreceptor systems in microalgae. Micron 32, 411-426. doi: 10.1016/S0968-4328(00)00016-0

Guerra-Blanco, P., Cortes, O., Poznyak, T., Chairez, I., and García-Peña, E. I. (2018). Polyhydroxyalkanoates (PHA) production by photoheterotrophic microbial consortia: effect of culture conditions over microbial population and biopolymer yield and composition. Eur. Polym. J. 98, 94-104. doi: 10.1016/j.eurpolymj.2017.11.007

Gurieff, N., and Lant, P. (2007). Comparative life cycle assessment and financial analysis of mixed culture polyhydroxyalkanoate production. Bioresour. Technol. 98, 3393-3403. doi: 10.1016/j.biortech.2006.10.046

Harding, K. G., Dennis, J. S., Von Blottnitz, H., and Harrison, S. T. L. (2007). Environmental analysis of plastic production processes: comparing petroleumbased polypropylene and polyethylene with biologically-based poly- $\beta$ hydroxybutyric acid using life cycle analysis. J. Biotechnol. 130, 57-66. doi: 10.1016/j.jbiotec.2007.02.012

Hartmann, R., Hany, R., Pletscher, E., Ritter, A., Witholt, B., and Zinn, M. (2006). Tailor-made olefinic medium-chain-length poly [(R)-3hydroxyalkanoates] by pseudomonas putida GPol: batch versus chemostat production. Biotechnol. Bioeng. 93, 737-746. doi: 10.1002/bit.20756

Hempel, F., Bozarth, A. S., Lindenkamp, N., Klingl, A., Zauner, S., Linne, U., et al. (2011). Microalgae as bioreactors for bioplastic production. Microb. Cell Factories 10, 1-6. doi: 10.1186/1475-2859-10-81

Higuchi-Takeuchi, M., Morisaki, K., Toyooka, K., and Numata, K. (2016). Synthesis of high-molecular-weight polyhydroxyalkanoates by marine photosynthetic purple bacteria. PLoS One 11, 1-17. doi: 10.1371/journal. pone. 0160981

Higuchi-Takeuchi, M., and Numata, K. (2019). Acetate-inducing metabolic states enhance Polyhydroxyalkanoate production in marine purple non-sulfur bacteria Under aerobic conditions. Front. Bioeng. Biotechnol. 7, 1-10. doi: 10.3389/fbioe.2019.00118

Ho, S.-H., Chen, C.-N. N., Lai, Y.-Y., Lu, W.-B., and Chang, J.-S. (2014). Exploring the high lipid production potential of a thermotolerant microalga using statistical optimization and semi-continuous cultivation. Bioresour. Technol. 163, 128-135. doi: 10.1016/j.biortech.2014.04.028

Ho, S.-H., Huang, S.-W., Chen, C.-Y., Hasunuma, T., Kondo, A., and Chang, J.S. (2013). Bioethanol production using carbohydrate-rich microalgae biomass as feedstock. Bioresour. Technol. 135, 191-198. doi: 10.1016/j.biortech.2012. 10.015

Hoarau, J., Caro, Y., Grondin, I., and Petit, T. (2018). Sugarcane vinasse processing: Toward a status shift from waste to valuable resource. A review. J. water Process Eng. 24, 11-25. doi: 10.1016/j.jwpe.2018.05.003

Hoffmann, N., Amara, A. A., Beermann, B. B., Qi, Q., Hinz, H.-J., and Rehm, B. H. A. (2002). Biochemical characterization of the pseudomonas putida 3-hydroxyacyl ACP: CoA transacylase, which diverts intermediates of fatty acid de novo biosynthesis. J. Biol. Chem. 277, 42926-42936. doi: 10.1074/jbc.M207821200

Hossain, A. B. M. S., Salleh, A., Boyce, A. N., Chowdhury, P., and Naqiuddin, M. (2008). Biodiesel fuel production from algae as renewable energy. Am. J. Biochem. Biotechnol. 4, 250-254.

Jendrossek, D. (2009). Polyhydroxyalkanoate granules are complex subcellular organelles (carbonosomes). J. Bacteriol. 191, 3195-3202. doi: 10.1128/ JB.01723-08

Jiang, Y., Hebly, M., Kleerebezem, R., Muyzer, G., and van Loosdrecht, M. C. M. (2011a). Metabolic modeling of mixed substrate uptake for polyhydroxyalkanoate (PHA) production. Water Res. 45, 1309-1321. doi: 10.1016/j.watres.2010.10.009

Jiang, Y., Marang, L., Kleerebezem, R., Muyzer, G., and van Loosdrecht, M. C. M. (2011b). Polyhydroxybutyrate production from lactate using a mixed microbial culture. Biotechnol. Bioeng. 108, 2022-2035. doi: 10.1002/bit.23148

Jiang, Y., Marang, L., Kleerebezem, R., Muyzer, G., and Van Loosdrecht, M. C. M. (2011c). Effect of temperature and cycle length on microbial competition in PHB-producing sequencing batch reactor. ISME J. 5, 896-907. doi: 10.1038/ ismej.2010.174

Johnson, K., Jiang, Y., Kleerebezem, R., Muyzer, G., and Van Loosdrecht, M. C. M. (2009). Enrichment of a mixed bacterial culture with a high polyhydroxyalkanoate storage capacity. Biomacromolecules 10, 670-676. doi: $10.1021 / \mathrm{bm} 8013796$

Johnson, K., Kleerebezem, R., and van Loosdrecht, M. C. M. (2010). Influence of the $\mathrm{C} / \mathrm{N}$ ratio on the performance of polyhydroxybutyrate (PHB) producing 
sequencing batch reactors at short SRTs. Water Res. 44, 2141-2152. doi: 10.1016/j.watres.2009.12.031

Jung, Y.-M., and Lee, Y.-H. (2000). Utilization of oxidative pressure for enhanced production of poly- $\beta$-hydroxybutyrate and poly (3-hydroxybutyrate-3hydroxyvalerate) in Ralstonia eutropha. J. Biosci. Bioeng. 90, 266-270. doi: 10.1016/S1389-1723(00)80080-8

Jung, Y. M., Park, J. S., and Lee, Y. H. (2000). Metabolic engineering of Alcaligenes eutrophus through the transformation of cloned phbCAB genes for the investigation of the regulatory mechanism of polyhydroxyalkanoate biosynthesis. Enzym. Microb. Technol. 26, 201-208. doi: 10.1016/ S0141-0229(99)00156-8

Jungmeier, G. (2014). "The biorefinery complexity index," in IEA-Bioenergy Task, Vol. 42, 36. EIA Bioenegy.

Kadouri, D., Jurkevitch, E., Okon, Y., and Castro-Sowinski, S. (2005). Ecological and agricultural significance of bacterial polyhydroxyalkanoates. Crit. Rev. Microbiol. 31, 55-67. doi: 10.1080/10408410590899228

Kaeb, H., Aeschelmann, F., Dammer, L., and Carus, M. (2016). Market Study on the Consumption of Biodegradable and Compostable Plastic Products in Europe 2015 and 2020. Germany: Nova-Institute Hürth, 6.

Kai, D., and Loh, X. J. (2014). Polyhydroxyalkanoates: chemical modifications toward biomedical applications. ACS Sustain. Chem. Eng. 2, 106-119. doi: $10.1021 / \mathrm{sc} 400340 \mathrm{p}$

Kamravamanesh, D., Kovacs, T., Pflügl, S., Druzhinina, I., Kroll, P., Lackner, M., et al. (2018). Increased poly-B-hydroxybutyrate production from carbon dioxide in randomly mutated cells of cyanobacterial strain Synechocystis sp. PCC 6714: mutant generation and characterization. Bioresour. Technol. 266, 34-44. doi: 10.1016/j.biortech.2018.06.057

Kamravamanesh, D., Pflügl, S., Nischkauer, W., Limbeck, A., Lackner, M., and Herwig, C. (2017). Photosynthetic poly- $\beta$-hydroxybutyrate accumulation in unicellular cyanobacterium Synechocystis sp. PCC 6714. AMB express 7, 1-12. doi: 10.1186/s13568-017-0443-9

Karan, H., Funk, C., Grabert, M., Oey, M., and Hankamer, B. (2019). Green bioplastics as part of a circular bioeconomy. Trends Plant Sci. 24, 237-249. doi: 10.1016/j.tplants.2018.11.010

Kato, N. (2019). Production of crude bioplastic-beads with microalgae: proofof-concept. Bioresour. Technol. Rep. 6, 81-84. doi: 10.1016/j.biteb.2019.01.022

Kavitha, G., Kurinjimalar, C., Sivakumar, K., Kaarthik, M., Aravind, R., Palani, P., et al. (2016a). Optimization of polyhydroxybutyrate production utilizing waste water as nutrient source by Botryococcus braunii Kütz using response surface methodology. Int. J. Biol. Macromol. 93, 534-542. doi: 10.1016/j. ijbiomac.2016.09.019

Kavitha, G., Kurinjimalar, C., Sivakumar, K., Palani, P., and Rengasamy, R. (2016b). Biosynthesis, purification and characterization of polyhydroxybutyrate from Botryococcus braunii kütz. Int. J. Biol. Macromol. 89, 700-706. doi: 10.1016/j.ijbiomac.2016.04.086

Keskin, G., Klzll, G., Bechelany, M., Pochat-Bohatier, C., and Öner, M. (2017). Potential of polyhydroxyalkanoate (PHA) polymers family as substitutes of petroleum based polymers for packaging applications and solutions brought by their composites to form barrier materials. Pure Appl. Chem. 89, 1841-1848. doi: 10.1515/pac-2017-0401

Kim, H., Lee, S., Ahn, Y., Lee, J., and Won, W. (2020). Sustainable production of bioplastics from lignocellulosic biomass: technoeconomic analysis and life-cycle assessment. ACS Sustain. Chem. Eng. 8, 12419-12429. doi: 10.1021/ acssuschemeng.0c02872

Kiran, B., Kumar, R., and Deshmukh, D. (2014). Perspectives of microalgal biofuels as a renewable source of energy. Energy Convers. Manag. 88, 1228-1244. doi: 10.1016/j.enconman.2014.06.022

Kitamura, S., and Doi, Y. (1994). Staining method of poly(3-hydroxyalkanoic acids) producing bacteria by nile blue. Biotechnol. Tech. 8, 345-350. doi: 10.1007/BF02428979

Koller, M., Atlić, A., Dias, M., Reiterer, A., and Braunegg, G. (2010). "Microbial PHA production from waste raw materials," in Plastics From Bacteria (Germany: Springer), 85-119.

Koller, M., Niebelschütz, H., and Braunegg, G. (2013). Strategies for recovery and purification of poly [(R)-3-hydroxyalkanoates](PHA) biopolyesters from surrounding biomass. Eng. Life Sci. 13, 549-562. doi: 10.1002/elsc.201 300021

Kourmentza, C., Plácido, J., Venetsaneas, N., Burniol-Figols, A., Varrone, C., Gavala, H. N., et al. (2017). Recent advances and challenges towards sustainable
Polyhydroxyalkanoate (PHA) production. Bioengineering 4:55. doi: 10.3390/ bioengineering4020055

Kshirsagar, P., Suttar, R., Nilegaonkar, S., and Kulkarni, S. (2013). Scale up production of polyhydroxyalkanoate (PHA) at different aeration, agitation and controlled dissolved oxygen levels in fermenter using Halomonas campisalis MCM B-1027. J. Biochem. Technol. 4, 512-517.

Kunasundari, B., and Sudesh, K. (2011). Isolation and recovery of microbial polyhydroxyalkanoates. Express Polym Lett 5, 620-634. doi: 10.3144/ expresspolymlett.2011.60

Kurian, N. S., and Das, B. (2021). Comparative analysis of various extraction processes based on economy, eco-friendly, purity and recovery of polyhydroxyalkanoate: A review. Int. J. Biol. Macromol. 183, 1881-1890. doi: 10.1016/j.ijbiomac.2021.06.007

Laurens, L. M. L., Markham, J., Templeton, D. W., Christensen, E. D., Van Wychen, S., Vadelius, E. W., et al. (2017). Development of algae biorefinery concepts for biofuels and bioproducts; a perspective on process-compatible products and their impact on cost-reduction. Energy Environ. Sci. 10, 1716-1738. doi: 10.1039/C7EE01306J

Laycock, B., Arcos-Hernandez, M. V., Langford, A., Pratt, S., Werker, A., Halley, P. J., et al. (2014). Crystallisation and fractionation of selected polyhydroxyalkanoates produced from mixed cultures. New Biotechnol. 31, 345-356. doi: 10.1016/j.nbt.2013.05.005

Le Meur, S., Zinn, M., Egli, T., Thöny-Meyer, L., and Ren, Q. (2012). Production of medium-chain-length polyhydroxyalkanoates by sequential feeding of xylose and octanoic acid in engineered pseudomonas putida KT2440. BMC Biotechnol. 12, 1-12. doi: 10.1186/1472-6750-12-53

Lee, S. Y. (1996). Bacterial polyhydroxyalkanoates. Biotechnol. Bioeng. 49, 1-14. doi: 10.1002/(SICI)1097-0290(19960105)49:1<1::AID-BIT1>3.0.CO;2-P

Lee, M. W., Han, S. O., and Seo, Y. B. (2008). Red algae fibre/poly (butylene succinate) biocomposites: the effect of fibre content on their mechanical and thermal properties. Compos. Sci. Technol. 68, 1266-1272. doi: 10.1016/j. compscitech.2007.12.016

Lee, S. H., Oh, D. H., Ahn, W. S., Lee, Y., Choi, J. I., and Lee, S. Y. (2000). Production of poly(3-hydroxybutyrate-co-3-hydroxyhexanoate) by high- celldensity cultivation of Aeromonas hydrophila. Biotechnol. Bioeng. 67, 240-244. doi: 10.1002/(SICI)1097-0290(20000120)67:2<240::AID-BIT14>3.0.CO;2-F

Lemoigne, M. (1926). Products of dehydration and of polymerization of $\beta$-hydroxybutyric acid. Bull. Soc. Chem. Biol. 8, 770-782.

Li, M., Wijewardane, N. K., Ge, Y., Xu, Z., and Wilkins, M. R. (2020). Visible/ near infrared spectroscopy and machine learning for predicting polyhydroxybutyrate production cultured on alkaline pretreated liquor from corn Stover. Bioresour. Technol. Reports 9:100386. doi: 10.1016/j. biteb.2020.100386

Liu, Q., Luo, G., Zhou, X. R., and Chen, G.-Q. (2011). Biosynthesis of poly (3-hydroxydecanoate) and 3-hydroxydodecanoate dominating polyhydroxyalkanoates by $\beta$-oxidation pathway inhibited pseudomonas putida. Metab. Eng. 13, 11-17. doi: 10.1016/j.ymben.2010.10.004

Llamas, M., Magdalena, J. A., Tomás-Pejó, E., and González-Fernández, C. (2020). Microalgae-based anaerobic fermentation as a promising technology for producing biogas and microbial oils. Energy 206:118184. doi: 10.1016/j. energy.2020.118184

Lorini, L., Martinelli, A., Pavan, P., Majone, M., and Valentino, F. (2021). Downstream processing and characterization of polyhydroxyalkanoates (PHAs) produced by mixed microbial culture (MMC) and organic urban waste as substrate. Biomass Conversion and Biorefinery 11, 693-703. doi: 10.1007/ s13399-020-00788-w

Löwe, H., Hobmeier, K., Moos, M., Kremling, A., and Pflüger-Grau, K. (2017). Photoautotrophic production of polyhydroxyalkanoates in a synthetic mixed culture of Synechococcus elongatus $\operatorname{cscB}$ and pseudomonas putida cscAB. Biotechnol. Biofuels 10, 1-11. doi: 10.1186/s13068-017-0875-0

Madison, L. L., and Huisman, G. W. (1999). Metabolic engineering of poly (3-hydroxyalkanoates): from DNA to plastic. Microbiol. Mol. Biol. Rev. 63, 21-53. doi: 10.1128/MMBR.63.1.21-53.1999

Maheswari, N. U., and Ahilandeswari, K. (2011). Production of bioplastic using Spirulina platensis and comparison with commercial plastic. Res. Environ. Life Sci 4, 133-136.

Mallick, N., Gupta, S., Panda, B., and Sen, R. (2007). Process optimization for poly (3-hydroxybutyrate-co-3-hydroxyvalerate) co-polymer production by Nostoc muscorum. Biochem. Eng. J. 37, 125-130. doi: 10.1016/j.bej.2007.04.002 
Marang, L., Jiang, Y., van Loosdrecht, M. C. M., and Kleerebezem, R. (2013). Butyrate as preferred substrate for polyhydroxybutyrate production. Bioresour. Technol. 142, 232-239. doi: 10.1016/j.biortech.2013.05.031

Markou, G., and Nerantzis, E. (2013). Microalgae for high-value compounds and biofuels production: a review with focus on cultivation under stress conditions. Biotechnol. Adv. 31, 1532-1542. doi: 10.1016/j.biotechadv. 2013.07.011

Martosa, E. M., Istratea, I.-R., and Dufoura, J. (2019). Wastewater Treatment Residues as Resources for Biorefinery Products and Biofuels. United States: Elsevier.

Mathiot, C., Ponge, P., Gallard, B., Sassi, J.-F., Delrue, F., and Le Moigne, N. (2019). Microalgae starch-based bioplastics: screening of ten strains and plasticization of unfractionated microalgae by extrusion. Carbohydr. Polym. 208, 142-151. doi: 10.1016/j.carbpol.2018.12.057

McChalicher, C. W. J., and Srienc, F. (2007). Investigating the structure-property relationship of bacterial PHA block copolymers. J. Biotechnol. 132, 296-302. doi: 10.1016/j.jbiotec.2007.04.014

Mohanrasu, K., Rao, R. G. R., Dinesh, G. H., Zhang, K., Prakash, G. S., Song, D. P., et al. (2020). Optimization of media components and culture conditions for polyhydroxyalkanoates production by bacillus megaterium. Fuel 271:117522. doi: 10.1016/j.fuel.2020.117522

Mothersole, D. J., Farmer, D. A., Hitchcock, A., and Hunter, C. N. (2018). "Photosynthetic apparatus in purple bacteria," in Light Harvesting in Photosynthesis (United States: CRC Press), 95-120.

Muhammadi, S., Afzal, M., and Hameed, S. (2015). Bacterial polyhydroxyalkanoates-eco-friendly next generation plastic: production, biocompatibility, biodegradation, physical properties and applications. Green Chem. Lett. Rev. 8, 56-77. doi: 10.1080/17518253.2015.1109715

Naheed, N. (2012). Biosynthesis of polyhydroxybutyrate in Enterobacter sp. SEL2 and Enterobacteriaceae bacterium sp. PFW1 using sugar cane molasses as media. African J. Biotechnol. 11, 3321-3332. doi: 10.5897/ajb11. 1405

Nakanishi, A., Aikawa, S., Ho, S.-H., Chen, C.-Y., Chang, J.-S., Hasunuma, T., et al. (2014). Development of lipid productivities under different CO2 conditions of marine microalgae Chlamydomonas sp. JSC4. Bioresour. Technol. 152, 247-252. doi: 10.1016/j.biortech.2013.11.009

Nazem-Bokaee, H., and Senger, R. S. (2015). ToMI-FBA: A genome-scale metabolic flux based algorithm to select optimum hosts and media formulations for expressing pathways of interest. AIMS Bioeng. 2, 335-374. doi: 10.3934/ bioeng.2015.4.335

Nduko, J. M., Matsumoto, K., Ooi, T., and Taguchi, S. (2013). Effectiveness of xylose utilization for high yield production of lactate-enriched $\mathrm{P}($ lactateco-3-hydroxybutyrate) using a lactate-overproducing strain of Escherichia coli and an evolved lactate-polymerizing enzyme. Metab. Eng. 15, 159-166. doi: 10.1016/j.ymben.2012.11.007

Nikel, P. I., De Almeida, A., Melillo, E. C., Galvagno, M. A., and Pettinari, M. J. (2006). New recombinant Escherichia coli strain tailored for the production of poly(3-hydroxybutyrate) from agroindustrial by-products. Appl. Environ. Microbiol. 72, 3949-3954. doi: 10.1128/AEM.00044-06

Nishioka, M., Nakai, K., Miyake, M., Asada, Y., and Taya, M. (2001). Production of poly- $\beta$-hydroxybutyrate by thermophilic cyanobacterium, Synechococcus sp. MA19, under phosphate-limited conditions. Biotechnol. Lett. 23, 1095-1099. doi: 10.1023/A:1010551614648

Nobu, M. K., Tamaki, H., Kubota, K., and Liu, W. T. (2014). Metagenomic characterization of "CandidatusDefluviicoccus tetraformis strain TFO71", a tetrad-forming organism, predominant in an anaerobic-aerobic membrane bioreactor with deteriorated biological phosphorus removal. Environ. Microbiol. 16, 2739-2751. doi: 10.1111/1462-2920.12383

Noreen, A., Zia, K. M., Zuber, M., Ali, M., and Mujahid, M. (2016). A critical review of algal biomass: A versatile platform of bio-based polyesters from renewable resources. Int. J. Biol. Macromol. 86, 937-949. doi: 10.1016/j. ijbiomac.2016.01.067

Obruca, S., Petrik, S., Benesova, P., Svoboda, Z., Eremka, L., and Marova, I. (2014). Utilization of oil extracted from spent coffee grounds for sustainable production of polyhydroxyalkanoates. Appl. Microbiol. Biotechnol. 98, 5883-5890. doi: 10.1007/s00253-014-5653-3

Ogbonna, J. C., Yoshizawa, H., and Tanaka, H. (2000). Treatment of high strength organic wastewater by a mixed culture of photosynthetic microorganisms. J. Appl. Phycol. 12, 277-284. doi: 10.1023/A:1008188311681
Oliveira, C. S. S., Silva, C. E., Carvalho, G., and Reis, M. A. (2017). Strategies for efficiently selecting PHA producing mixed microbial cultures using complex feedstocks: feast and famine regime and uncoupled carbon and nitrogen availabilities. New Biotechnol. 37, 69-79. doi: 10.1016/j.nbt.2016.10.008

Otsuki, T., Zhang, F., Kabeya, H., and Hirotsu, T. (2004). Synthesis and tensile properties of a novel composite of chlorella and polyethylene. J. Appl. Polym. Sci. 92, 812-816. doi: 10.1002/app. 13650

Ouyang, P., Wang, H., Hajnal, I., Wu, Q., Guo, Y., and Chen, G.-Q. (2018). Increasing oxygen availability for improving poly (3-hydroxybutyrate) production by Halomonas. Metab. Eng. 45, 20-31. doi: 10.1016/j. ymben.2017.11.006

Pakalapati, H., Chang, C. K., Show, P. L., Arumugasamy, S. K., and Lan, J. C. W. (2018). Development of polyhydroxyalkanoates production from waste feedstocks and applications. J. Biosci. Bioeng. 126, 282-292. doi: 10.1016/j. jbiosc.2018.03.016

Panda, B., and Mallick, N. (2007). Enhanced poly- b -hydroxybutyrate accumulation in a unicellular cyanobacterium, Synechocystis sp. PCC 6803. Lett. Appl. Microbiol. 44, 194-198. doi: 10.1111/j.1472-765X.2006.02048.x

Papapostolou, A., Karasavvas, E., and Chatzidoukas, C. (2019). Oxygen mass transfer limitations set the performance boundaries of microbial PHA production processes - A model-based problem investigation supporting scale-up studies. Biochem. Eng. J. 148, 224-238. doi: 10.1016/j.bej. 2019.04.024

Pardelha, F., Albuquerque, M. G. E., Carvalho, G., Reis, M. A. M., Dias, J. M. L., and Oliveira, R. (2013). Segregated flux balance analysis constrained by population structure/function data: the case of PHA production by mixed microbial cultures. Biotechnol. Bioeng. 110, 2267-2276. doi: 10.1002/bit.24894

Peplinski, K., Ehrenreich, A., Döring, C., Bömeke, M., Reinecke, F., Hutmacher, C., et al. (2010). Genome-wide transcriptome analyses of the "Knallgas" bacterium Ralstonia eutropha H16 with regard to polyhydroxyalkanoate metabolism. Microbiology 156, 2136-2152. doi: 10.1099/mic.0.038380-0

Pereira, J., Queirós, D., Lemos, P. C., Rossetti, S., and Serafim, L. S. (2020). Enrichment of a mixed microbial culture of PHA-storing microorganisms by using fermented hardwood spent sulfite liquor. New Biotechnol. 56, 79-86. doi: $10.1016 /$ j.nbt.2019.12.003

Perez-Garcia, O., Escalante, F. M. E., De-Bashan, L. E., and Bashan, Y. (2011). Heterotrophic cultures of microalgae: metabolism and potential products. Water Res. 45, 11-36. doi: 10.1016/j.watres.2010.08.037

Pérez, V., Mota, C. R., Muñoz, R., and Lebrero, R. (2020). Polyhydroxyalkanoates (PHA) production from biogas in waste treatment facilities: Assessing the potential impacts on economy, environment and society. Chemosphere 255:126929. doi: 10.1016/j.chemosphere.2020.126929

Povolo, S., Toffano, P., Basaglia, M., and Casella, S. (2010). Polyhydroxyalkanoates production by engineered Cupriavidus necator from waste material containing lactose. Bioresour. Technol. 101, 7902-7907. doi: 10.1016/j.biortech.2010.05. 029

Price, S., Kuzhiumparambil, U., Pernice, M., and Ralph, P. J. (2020). Cyanobacterial polyhydroxybutyrate for sustainable bioplastic production: critical review and perspectives. J. Environ. Chem. Eng. 8:104007. doi: 10.1016/j. jece.2020.104007

Qiu, Y. Z., Han, J., Guo, J. J., and Chen, G. Q. (2005). Production of poly(3hydroxybutyrate-co-3-hydroxyhexanoate) from gluconate and glucose by recombinant Aeromonas hydrophila and pseudomonas putida. Biotechnol. Lett. 27, 1381-1386. doi: 10.1007/s10529-005-3685-6

Rahman, A., and Miller, C. D. (2017). "Microalgae as a source of bioplastics," in Algal Green Chemistry (Netherlands: Elsevier), 121-138.

Rehm, B. H. A. (2003). Polyester synthases: natural catalysts for plastics. Biochem. J. 376, 15-33. doi: 10.1042/bj20031254

Rehm, B. H. A., Krüger, N., and Steinbüchel, A. (1998). A new metabolic link between fatty acid de NovoSynthesis and Polyhydroxyalkanoic acid synthesis: The PHAG gene From pseudomonas putida KT2440 encodes a 3-Hydroxyacylacyl carrier protein-coenzyme A transferase. J. Biol. Chem. 273, 24044-24051. doi: $10.1074 /$ jbc.273.37.24044

Rehm, B. H. A., and Steinbüchel, A. (1999). Biochemical and genetic analysis of PHA synthases and other proteins required for PHA synthesis. Int. J. Biol. Macromol. 25, 3-19. doi: 10.1016/S0141-8130(99)00010-0

Riedel, S., and Brigham, C. (2020). "Inexpensive and waste raw materials for PHAProduction," in The Handbook of Polyhydroxyalkanoates (United States: CRC Press), 203-220. 
Rocha, C. J. L., Álvarez-Castillo, E., Estrada Yáñez, M. R., Bengoechea, C., Guerrero, A., and Orta Ledesma, M. T. (2020). Development of bioplastics from a microalgae consortium from wastewater. J. Environ. Manag. 263:110353. doi: 10.1016/j.jenvman.2020.110353

Roja, K., Sudhakar, D. R., Anto, S., and Mathimani, T. (2019). Extraction and characterization of polyhydroxyalkanoates from marine green alga and cyanobacteria. Biocatal. Agric. Biotechnol. 22:101358. doi: 10.1016/j. bcab.2019.101358

Rosso, D., Larson, L. E., and Stenstrom, M. K. (2008). Aeration of large-scale municipal wastewater treatment plants: state of the art. Water Sci. Technol. 57, 973-978. doi: 10.2166/wst.2008.218

Sabathini, H. A., Windiani, L., and Gozan, M. (2018). Mechanical Physicial properties of chlorella-PVA based bioplastic with ultrasonic homogenizer. In E3S web of conferences. EDP Sci. 67:3046. doi: 10.1051/e3sconf/20186703046

Safonova, E., Kvitko, K. V., Iankevitch, M. I., Surgko, L. F., Afti, I. A., and Reisser, W. (2004). Biotreatment of industrial wastewater by selected algalbacterial consortia. Eng. Life Sci. 4, 347-353. doi: 10.1002/elsc.200420039

Salehizadeh, H., and Van Loosdrecht, M. C. M. (2004). Production of polyhydroxyalkanoates by mixed culture: recent trends and biotechnological importance. Biotechnol. Adv. 22, 261-279. doi: 10.1016/j.biotechadv. 2003.09.003

Samantaray, S., and Mallick, N. (2014). Production of poly(3-hydroxybutyrateco-3-hydroxyvalerate) co-polymer by the diazotrophic cyanobacterium Aulosira fertilissima CCC 444. J. Appl. Phycol. 26, 237-245. doi: 10.1007/ s10811-013-0073-9

Samantaray, S., and Mallick, N. (2015). Impact of various stress conditions on poly- $\beta$-hydroxybutyrate (PHB) accumulation in Aulosira fertilissima CCC 444. Curr. Biotechnol. 4, 366-372. doi: 10.2174/22115501046661 50806000642

Sanhueza, C., Diaz-Rodriguez, P., Villegas, P., González, Á., Seeger, M., Suárez-González, J., et al. (2020). Influence of the carbon source on the properties of poly-(3)-hydroxybutyrate produced by Paraburkholderia xenovorans LB400 and its electrospun fibers. Int. J. Biol. Macromol. 152, 11-20. doi: 10.1016/j.ijbiomac.2020.02.080

Schmid, J., Sieber, V., and Rehm, B. (2015). Bacterial exopolysaccharides: biosynthesis pathways and engineering strategies. Front. Microbiol. 6:496. doi: $10.3389 /$ fmicb.2015.00496

Schubert, P., Steinbüchel, A., and Schlegel, H. G. (1988). Cloning of the Alcaligenes eutrophus genes for synthesis of poly-beta-hydroxybutyric acid (PHB) and synthesis of PHB in Escherichia coli. J. Bacteriol. 170, 5837-5847. doi: 10.1128/jb.170.12.5837-5847.1988

Schwenzfeier, A., Wierenga, P. A., and Gruppen, H. (2011). Isolation and characterization of soluble protein from the green microalgae Tetraselmis sp. Bioresour. Technol. 102, 9121-9127. doi: 10.1016/j.biortech.2011.07.046

Sciarria, T. P., Batlle-Vilanova, P., Colombo, B., Scaglia, B., Balaguer, M. D., Colprim, J., et al. (2018). Bio-electrorecycling of carbon dioxide into bioplastics. Green Chem. 20, 4058-4066. doi: 10.1039/C8GC01771A

Serafim, L. S., Lemos, P. C., Rossetti, S., Levantesi, C., Tandoi, V., and Reis, M. A. M. (2006). Microbial community analysis with a high PHA storage capacity. Water Sci. Technol. 54, 183-188. doi: 10.2166/wst.2006.386

Shafqat, A., Tahir, A., Mahmood, A., and Pugazhendhi, A. (2020). A review on environmental significance carbon foot prints of starch based bio-plastic: A substitute of conventional plastics. Biocatal. Agric. Biotechnol. 27:101540. doi: $10.1016 /$ j.bcab.2020.101540

Sharma, L., and Mallick, N. (2005). Accumulation of poly- $\beta$-hydroxybutyrate in Nostoc muscorum: regulation by $\mathrm{pH}$, light-dark cycles, $\mathrm{N}$ and $\mathrm{P}$ status and carbon sources. Bioresour. Technol. 96, 1304-1310. doi: 10.1016/j. biortech.2004.10.009

Shi, B., Wideman, G., and Wang, J. H. (2012). A New Approach of BioCO 2 Fixation by Thermoplastic Processing of Microalgae. J. Polym. Environ. 20, 124-131. doi: 10.1007/s10924-011-0329-x

Silva, F., Campanari, S., Matteo, S., Valentino, F., Majone, M., and Villano, M. (2017). Impact of nitrogen feeding regulation on polyhydroxyalkanoates production by mixed microbial cultures. New Biotechnol. 37, 90-98. doi: 10.1016/j.nbt.2016.07.013

Simon, A., Anton, B., Tomas, K., Simon, F. M., and Monica, A. (2016). A process for polyhydroxyalkanoate (PHA) production from municipal wastewater treatment with biological carbon and nitrogen removal demonstrated at pilot-scale. New Biotechnol. 35, 42-53. doi: 10.1016/j.nbt.2016.11.005
Singh, A. K., Sharma, L., Mallick, N., and Mala, J. (2017). Progress and challenges in producing polyhydroxyalkanoate biopolymers from cyanobacteria. J. Appl. Phycol. 29, 1213-1232. doi: 10.1007/s10811-016-1006-1

Solaiman, D. K. Y., Ashby, R. D., Foglia, T. A., and Marmer, W. N. (2006). Conversion of agricultural feedstock and coproducts into poly(hydroxyalkanoates). Appl. Microbiol. Biotechnol. 71, 783-789. doi: 10.1007/ s00253-006-0451-1

Steinbüchel, A., and Füchtenbusch, B. (1998). Bacterial and other biological systems for polyester production. Trends Biotechnol. 16, 419-427. doi: 10.1016/ S0167-7799(98)01194-9

Steinbüchel, A., Hustede, E., Liebergesell, M., Pieper, U., Timm, A., and Valentin, H. (1992). Molecular basis for biosynthesis and accumulation of polyhydroxyalkanoic acids in bacteria. FEMS Microbiol. Rev. 9, 217-230. doi: 10.1111/j.1574-6968.1992.tb05841.x

Steinbüchel, A., and Lütke-Eversloh, T. (2003). Metabolic engineering and pathway construction for biotechnological production of relevant polyhydroxyalkanoates in microorganisms. Biochem. Eng. J. 16, 81-96. doi: 10.1016/S1369-703X(03)00036-6

Steinbüchel, A., and Wiese, S. (1992). A pseudomonas strain accumulating polyesters of 3-hydroxybutyric acid and medium-chain-length 3-hydroxyalkanoic acids. Appl. Microbiol. Biotechnol. 37, 691-697. doi: 10.1007/ BF00174829

Sun, Z., Ramsay, J. A., Guay, M., and Ramsay, B. A. (2007). Carbon-limited fed-batch production of medium-chain-length polyhydroxyalkanoates from nonanoic acid by pseudomonas putida KT2440. Appl. Microbiol. Biotechnol. 74, 69-77. doi: 10.1007/s00253-006-0655-4

Talaiekhozani, A., and Rezania, S. (2017). Application of photosynthetic bacteria for removal of heavy metals, macro-pollutants and dye from wastewater: A review. J. Water Process Eng. 19, 312-321. doi: 10.1016/j.jwpe.2017.09.004

Ten, E., Jiang, L., Zhang, J., and Wolcott, M. P. (2015). Mechanical performance of polyhydroxyalkanoate (PHA)-based biocomposites. Biocomposites, 39-52. doi: 10.1016/B978-1-78242-373-7.00008-1

Tamang, P., Banerjee, R., Köster, S., and Nogueira, R. (2019). Comparative study of polyhydroxyalkanoates production from acidified and anaerobically treated brewery wastewater using enriched mixed microbial culture. J. Environ. Sci. 78, 137-146. doi: 10.1016/J.JES.2018.09.001

Toh, P., Jau, M. H., Yew, S.-P., Abed, R., and Sudesh, K. (2008). Comparison of polyhydroxyalkonates biosynthesis, mobilization and the effects of cellular morphology in Spirulina platensis and Synechocystis sp. Uniwg. J. Biosci. 19, 21-38.

Toro, C., Reddy, M. M., Navia, R., Rivas, M., Misra, M., and Mohanty, A. K. (2013). Characterization and application in biocomposites of residual microalgal biomass generated in third generation biodiesel. J. Polym. Environ. 21, 944-951. doi: 10.1007/s10924-013-0609-8

Torres, S., Navia, R., Campbell Murdy, R., Cooke, P., Misra, M., and Mohanty, A. K. (2015). Green composites from residual microalgae biomass and poly (butylene adipate-co-terephthalate): processing and plasticization. ACS Sustain. Chem. Eng. 3, 614-624. doi: 10.1021/sc500753h

Trivedi, J., Aila, M., Bangwal, D. P., Kaul, S., and Garg, M. O. (2015). Algae based biorefinery-how to make sense? Renew. Sust. Energ. Rev. 47, 295-307. doi: 10.1016/j.rser.2015.03.052

Troschl, C., Meixner, K., and Drosg, B. (2017). Cyanobacterial PHA productionreview of recent advances and a summary of three years' working experience running a pilot plant. Bioengineering 4:26. doi: 10.3390/bioengineering4020026

Troschl, C., Meixner, K., Fritz, I., Leitner, K., Romero, A. P., Kovalcik, A., et al. (2018). Pilot-scale production of poly- $\beta$-hydroxybutyrate with the cyanobacterium Synechocytis sp. CCALA192 in a non-sterile tubular photobioreactor. Algal Res. 34, 116-125. doi: 10.1016/j.algal.2018.07.011

Van Iersel, S. (2009). Algae-based Biofuels. A Review of Challenges and Opportunities for Developing Countries.

Verlinden, R. A. J., Hill, D. J., Kenward, M. A., Williams, C. D., and Radecka, I. (2007). Bacterial synthesis of biodegradable polyhydroxyalkanoates. J. Appl. Microbiol. 102, 1437-1449. doi: 10.1111/j.1365-2672.2007.03335.x

Villano, M., Beccari, M., Dionisi, D., Lampis, S., Miccheli, A., Vallini, G., et al. (2010). Effect of $\mathrm{pH}$ on the production of bacterial polyhydroxyalkanoates by mixed cultures enriched under periodic feeding. Process Biochem. 45, 714-723. doi: 10.1016/j.procbio.2010.01.008

Volova, T., Demidenko, A., Kiselev, E., Baranovskiy, S., Shishatskaya, E., and Zhila, N. (2019). Polyhydroxyalkanoate synthesis based on glycerol and 
implementation of the process under conditions of pilot production. Appl. Microbiol. Biotechnol. 103, 225-237. doi: 10.1007/s00253-018-9460-0

Wang, D., Chen, Y., Zheng, X., Li, X., and Feng, L. (2013). Short-chain fatty acid production from different biological phosphorus removal sludges: the influences of PHA and gram-staining bacteria. Environ. Sci. Technol. 47, 2688-2695. doi: 10.1021/es304673s

Wang, F., and Lee, S. Y. (1997). Poly (3-hydroxybutyrate) production with high productivity and high polymer content by a fed-batch culture of Alcaligenes latus under nitrogen limitation. Appl. Environ. Microbiol. 63, 3703-3706. doi: $10.1128 / \mathrm{aem} \cdot 63.9 .3703-3706.1997$

Wang, X., Wang, S., He, F., Tolba, E., Schröder, H. C., Diehl-Seifert, B., et al. (2016). Polyphosphate as a bioactive and biodegradable implant material: induction of bone regeneration in rats. Adv. Eng. Mater. 18, 1406-1417. doi: $10.1002 /$ adem.201600057

Weiss, T. L., Young, E. J., and Ducat, D. C. (2017). A synthetic, light-driven consortium of cyanobacteria and heterotrophic bacteria enables stable polyhydroxybutyrate production. Metab. Eng. 44, 236-245. doi: 10.1016/j. ymben.2017.10.009

Wen, Y., Kierzek, K., Min, J., Chen, X., Gong, J., Niu, R., et al. (2020). Porous carbon nanosheet with high surface area derived from waste poly(ethylene terephthalate) for supercapacitor applications. J. Appl. Polym. Sci. 137, 1-10. doi: $10.1002 /$ app. 48338

Wendisch, V. F., Mindt, M., and Pérez-García, F. (2018). Biotechnological production of mono- and diamines using bacteria: recent progress, applications, and perspectives. Appl. Microbiol. Biotechnol. 102, 3583-3594. doi: 10.1007/ s00253-018-8890-z

Witholt, B., and Kessler, B. (1999). Perspectives of medium chain length poly (hydroxyalkanoates), a versatile set of bacterial bioplastics. Curr. Opin. Biotechnol. 10, 279-285. doi: 10.1016/S0958-1669(99)80049-4

Wong, Y. M., Brigham, C. J., Rha, C. K., Sinskey, A. J., and Sudesh, K. (2012). Biosynthesis and characterization of polyhydroxyalkanoate containing high 3-hydroxyhexanoate monomer fraction from crude palm kernel oil by recombinant Cupriavidus necator. Bioresour. Technol. 121, 320-327. doi: 10.1016/j.biortech.2012.07.015

Wu, C. S. (2012). Characterization and biodegradability of polyester bioplasticbased green renewable composites from agricultural residues. Polym. Degrad. Stab. 97, 64-71. doi: 10.1016/j.polymdegradstab. 2011.10.012
Wu, Q., Huang, H., Hu, G., Chen, J., Ho, K. P., and Chen, G. Q. (2001). Production of poly-3-hydroxybutrate by Bacillus sp. JMa5 cultivated in molasses media. Antonie van Leeuwenhoek. Int. J. Gen. Mol. Microbiol. 80, 111-118. doi: 10.1023/A:1012222625201

Zeller, M. A., Hunt, R., Jones, A., and Sharma, S. (2013). Bioplastics and their thermoplastic blends from spirulina and chlorella microalgae. J. Appl. Polym. Sci. 130, 3263-3275. doi: 10.1002/app.39559

Zhang, F., Endo, T., Kitagawa, R., Kabeya, H., and Hirotsu, T. (2000a). Synthesis and characterization of a novel blend of polypropylene with chlorella. $J$. Mater. Chem. 10, 2666-2672. doi: 10.1039/B004489J

Zhang, F., Kabeya, H., Kitagawa, R., Hirotsu, T., Yamashita, M., and Otsuki, T. (1999). Preparation and characterization of a novel polyethylene- chlorella composite. Chem. Mater. 11, 1952-1956. doi: 10.1021/cm990041y

Zhang, F., Kabeya, H., Kitagawa, R., Hirotsu, T., Yamashita, M., and Otsuki, T. (2000b). A novel polyethylene-chlorella composite. I. Characterization of chlorella biologically fixing CO2. J. Appl. Polym. Sci. 77, 2278-2284. doi: 10.1002/1097-4628(20000906)77:10<2278::AID-APP21>3.0.CO;2-Z

Zhang, J., Shishatskaya, E. I., Volova, T. G., da Silva, L. F., and Chen, G. Q. (2018). Polyhydroxyalkanoates (PHA) for therapeutic applications. Mater. Sci. Eng. C Mater. Biol. Appl. 86, 144-150. doi: 10.1016/j.msec.2017.12.035

Conflict of Interest: The authors declare that the research was conducted in the absence of any commercial or financial relationships that could be construed as a potential conflict of interest.

Publisher's Note: All claims expressed in this article are solely those of the authors and do not necessarily represent those of their affiliated organizations, or those of the publisher, the editors and the reviewers. Any product that may be evaluated in this article, or claim that may be made by its manufacturer, is not guaranteed or endorsed by the publisher.

Copyright (c) 2022 Samadhiya, Sangtani, Nogueira and Bala. This is an openaccess article distributed under the terms of the Creative Commons Attribution License (CC BY). The use, distribution or reproduction in other forums is permitted, provided the original author(s) and the copyright owner(s) are credited and that the original publication in this journal is cited, in accordance with accepted academic practice. No use, distribution or reproduction is permitted which does not comply with these terms. 